\title{
Influence of snow depth distribution on surface roughness in alpine terrain: a multi-scale approach
}

\author{
J. Veitinger ${ }^{1}$, B. Sovilla ${ }^{1}$, and R. S. Purves ${ }^{2}$ \\ ${ }^{1}$ WSL Institute for Snow and Avalanche Research SLF, Davos, Switzerland \\ ${ }^{2}$ Department of Geography, University of Zurich, Zurich, Switzerland \\ Correspondence to: J. Veitinger (veitinger@slf.ch) \\ Received: 16 July 2013 - Published in The Cryosphere Discuss.: 13 September 2013 \\ Revised: 17 January 2014 - Accepted: 18 February 2014 - Published: 3 April 2014
}

\begin{abstract}
In alpine terrain, the snow-covered winter surface deviates from its underlying summer terrain due to the progressive smoothing caused by snow accumulation. Terrain smoothing is believed to be an important factor in avalanche formation and avalanche dynamics, and it affects surface heat transfer, energy balance as well as snow depth distribution. To assess the effect of snow on terrain, we use an adequate roughness definition. We developed a method to quantify terrain smoothing by combining roughness calculations of snow surfaces and their corresponding underlying terrain with snow depth measurements. To this end, elevation models of winter and summer terrain in three selected alpine basins in the Swiss Alps characterized by low, medium and high terrain roughness were derived from highresolution measurements performed by airborne and terrestrial lidar. The preliminary results in the selected basins reveal that, at basin scale, terrain smoothing depends not only on mean snow depth in the basin but also on its variability. The multi-temporal analysis over three winter seasons in one basin suggests that terrain smoothing can be modelled as a function of mean snow depth and its standard deviation using a power law. However, a relationship between terrain smoothing and snow depth was not found at pixel scale. Further, we show that snow surface roughness is to some extent persistent, even in-between winter seasons. Those persistent patterns might be very useful to improve the representation of a winter terrain without modelling of the snow cover distribution. This can for example improve avalanche release area definition and, in the long term, natural hazard management strategies.
\end{abstract}

\section{Introduction}

During and after a snowfall event, wind, snow gliding and avalanches redistribute snow and smooth the geomorphology of the terrain by filling irregularities. During the snow accumulation season, terrain features successively disappear, leading to increasingly homogeneous deposition patterns during storm events and, thus, to a progressive smoothing of the terrain surface. Terrain smoothing influences albedo (e.g. Manninen et al., 2012), surface heat transfer and energy balance (e.g Fassnacht et al., 2009) and/or snow depth distribution (Mott et al., 2010). Whereas albedo is mainly affected by millimetre to centimetre changes of the winter terrain surface, snow distribution processes are modified by a changing winter topography at scales up to several tens of metres. Thus, understanding the multi-scale effects of snow smoothing on topography is very important in avalanche hazard assessment, run-off modelling and water resource management.

The evaluation of snow's influence on topography has always been an important task in avalanche risk assessment and hazard mapping. Terrain smoothing especially affects avalanche formation and dynamics. To correctly estimate the run-out distance of an avalanche, a precise estimation of the avalanche release area (as well as fracture depth) and the characteristics of the avalanche track (friction, etc.) are required. Both are influenced by terrain smoothing. Terrain smoothing in an avalanche path can change the friction between avalanche flow and the underlying terrain and thus has an impact on the avalanche dynamics. It is further important in determining the location and size of avalanche release areas. The evaluation of release area size is very complex 
and still typically requires considerable expert knowledge and experience. Existing tools for the automatic detection of avalanche release areas (e.g. Maggioni and Gruber, 2003; Bühler et al., 2013) are based exclusively on topographical parameters and are therefore mainly suited for the definition of extreme avalanches whose extents are strongly controlled by topography. These algorithms often fail to estimate smaller avalanche release areas that vary in location and size within the same topographical basin as they neglect the effect of variations in snow cover distribution. Changing snow deposition patterns due to terrain smoothing could thus partly explain the observed differences in release areas.

The importance of snow cover distribution in avalanche formation processes is well known and widely mentioned in the literature. One parameter particularly highlighted in this context is roughness. For a shallow snowpack, roughness can have a stabilizing function hindering the formation of continuous weak layers (Schweizer et al., 2003) and slabs (Simenhois and Birkeland, 2008) as well as providing mechanical support to the snowpack. McClung (2001) showed in a study of 76 avalanche paths due to clear-cut logging in the Coast and Columbia mountains of British Columbia that ground roughness (defined in a categorical way: (1) low: ground features smaller than $1 \mathrm{~m}$ relief; (2) medium: ground features 1-2 m relief; (3) high: ground features bigger than $2 \mathrm{~m}$ relief) is potentially important in inhibiting avalanche initiation. Actually, no events were reported in areas with roughness height larger than $2 \mathrm{~m}$. Moreover, van Herwijnen and Heierli (2009) stated that, in the case of weak layer failure, roughness of the bed surface plays an important role in determining whether an avalanche will release or not. However these stabilizing effects of terrain roughness disappear if the snowpack is deep enough to form a relatively smooth intermediate surface (McClung and Schaerer, 2002) where the formation of a homogenous snowpack with continuous weak layers and slabs is facilitated. All these studies demonstrate the ability of roughness to capture terrain smoothing as well as its importance in avalanche formation processes.

In recent years, airborne (Vallet, 2011; Fischer et al., 2011) and terrestrial laser scanning (Grünewald et al., 2010; Prokop, 2008; Prokop et al., 2008) have become increasingly reliable and feasible techniques to obtain high-resolution snow depth measurements even in steep alpine terrain, allowing analysis of snow depth distribution over multiple scales (Schirmer and Lehning, 2011; Deems et al., 2008; Trujillo et al., 2007). The importance of scale in snow redistribution is widely recognized. For instance it is known that snow redistribution patterns vary over scales due to different underlying processes (Blöschl, 1999). Winstral et al. (2002) suggested that one reason for the low percentage of snow depth variation that can be explained by terrain parameters might be differences in modelled processes and scales. Accordingly, methods like fractal analysis have been applied to evaluate snow depth variability over a wide range of scales (Schirmer and Lehning, 2011; Deems et al., 2008, 2006).
Snow depth generally showed two distinct regions of fractal scaling separated by a scale break where the dynamics of the underlying processes shaping the snow cover are supposed to change. Interestingly, these studies revealed very high interannual consistency of the fractal scaling behaviour of snow depth, suggesting that observed scaling properties are characteristic of the specific site and are relatively insensitive to variations in snow accumulation (Deems et al., 2008). This result was further strengthened by Schirmer et al. (2011), who found very high interannual consistency of snow depth measurements. Using a fractal roughness parameter, Lehning et al. (2011) established a statistical relationship between topography and snow depth in small topographical units. While Grünewald et al. (2013) showed that this behaviour is not universal, they stressed again the consistency of such statistical models at a given field site for consecutive years at times of maximum snow accumulation. Although these studies have brought valuable insight into snow depth distribution and its persistent topographical control in alpine terrain, little focus was put on how snow depth affects roughness of a winter terrain surface. Schirmer and Lehning (2011) interpreted the two distinct fractal scaling behaviours of snow depth in combination with increasing scale breaks in the accumulation season as smoothing of terrain roughness at increasing scales. Schweizer et al. (2003) stated that a snow depth of 0.3 to $1 \mathrm{~m}$ is required to eliminate terrain roughness. However, a consistent method to quantify the influence of snow depth on the geomorphology of a terrain surface integrating scale dependency and the temporal consistency of these processes has not been attempted yet.

In this study we provide a method to characterize and quantify the smoothing effects of snow on terrain based on high-resolution, multitemporal lidar measurements of summer and winter terrain. To this end, we derive local roughness estimates based on gemorphological parameters of winter and summer terrain. First, we develop a method to capture and quantify terrain smoothing at basin as well as at pixel scale as a function of snow depth parameters. We apply and discuss the method, using lidar data of three geomorphologically different basins within two alpine field sites in the Swiss Alps. Finally, we assess and quantify the persistence of snow depth and its corresponding terrain smoothing effects.

\section{Methods and data}

\subsection{Field sites and data acquisition}

We focus our study on three geomorphologically different basins located at two mountain test sites in the Swiss Alps (Fig. 1). The site of Vallée de la Sionne (VdlS) is located in the south-western part of Switzerland in the canton of Valais, near Sion. The terrain is characterized by elevations between 2460 and $2679 \mathrm{~m}$ a.s.l., and the orientation ranges from $\mathrm{E}$ to $\mathrm{SE}$. The VdlS field site is divided into two different 
basins characterized by distinct topography: Crêta Besse 1 (CB1) is steeper and rougher, whereas Crêta Besse 2 (CB2) is less steep and shows a very homogenous terrain surface without major ridges or cliffs. The area of the basin CB1 is $52600 \mathrm{~m}^{2}$; its mean slope is $42.4^{\circ}$ with a standard deviation of $6.0^{\circ}$. The area of the basin CB2 is $60700 \mathrm{~m}^{2}$, and it has a mean slope of $36.2^{\circ}$ with a standard deviation of $3.9^{\circ}$.

The Steintälli site (ST) is situated in the eastern part of Switzerland near Davos. The area of the basin is $73500 \mathrm{~m}^{2}$. The terrain is characterized by elevations between 2418 and $2600 \mathrm{~m}$ a.s.l., and the orientation ranges from NE through E to SE. Steep slopes are located near the ridge, flattening out in the lower part of the basin. The terrain surface is less rugged and irregular than in CB1 but still contains more topographical variety, such as gullies and rocky outcrops, than CB2. The mean slope of the basin is $35.6^{\circ}$ with a standard deviation of $7.3^{\circ}$. Slope maps of all basins are shown in Fig. 2. Further, all three basins represent areas where avalanches can potentially release (slope angle steeper than $28^{\circ}$ ).

Snow distribution in the Steintälli basin was determined by terrestrial laser scanning (TLS). The Riegl LPM-321 device, operating at $905 \mathrm{~nm}$, was used. This device has proven its ability to work in harsh alpine environment with sufficient accuracy (Prokop, 2008; Prokop et al., 2008). Grünewald et al. (2010) compared TLS with tachymeter measurements and found a mean deviation of $4 \mathrm{~cm}$ with a standard deviation of $5 \mathrm{~cm}$ at distances up to $250 \mathrm{~m}$. Our measurement distances ranged from 200 up to $600 \mathrm{~m}$; thus we estimate our vertical measurement accuracy of $20 \mathrm{~cm}$ or better. To ensure scan quality, we further performed reproducibility tests. We always performed a scan in coarse resolution in the beginning of the measurement campaign in addition to the normal laser scan acquisition. This allowed us in the post-processing to detect misalignments between the two, indicating possible errors due to an unstable scanner setup (stability of tripod, wind influence, etc.). Only scans with a mean deviation of less than $10 \mathrm{~cm}$ of the coarse scan were considered. We produced raster maps with a spatial resolution of $1 \mathrm{~m}$. We performed in total eight scans of the winter terrain between January and March within the winter seasons of 2010/11, $2011 / 12$ and 2012/13. An additional scan of the summer terrain was acquired on 18 September 2011 and serves as a reference for the snow depth calculations.

At the Vallée de la Sionne site, airborne laser scanning (ALS) measurements are performed before and after avalanche events using a helicopter-based system, and a detailed description of the method and the precision of the measurements can be found in Sovilla et al. (2010). The vertical accuracy of the data is $0.10 \mathrm{~m}$. We resampled the original grid from $0.5 \mathrm{~m}$ resolution to $1 \mathrm{~m}$ resolution using cubic interpolation to have the same spatial resolution as in Steintälli. At the Vallée de la Sionne test site, three ALS measurements were performed in three different winter seasons.

To calculate snow depth, the summer terrain was subtracted from the winter terrain and negative snow depth val- ues were excluded. Simple statistics were used to describe the snow depth distribution: Mean snow depth, $\overline{\mathrm{HS}}$, and its standard deviation, $\sigma(\mathrm{HS})$, as well as the coefficient of variation. The coefficient of variation, $C_{\mathrm{v}}$, is a normalized measure of the variability of the snowpack defined by the standard deviation divided by the mean snow depth:

$C_{\mathrm{v}}=\frac{\sigma(\mathrm{HS})}{\overline{\mathrm{HS}}}$.

The ST field site serves as an example for the exploitation of mulitemporal acquisitions over a larger time span (eight scans over three winter seasons). The comparison with the VdlS field site, where only three data sets are available, is intended to illustrate the differences with respect to different terrain morphology.

\subsection{Surface roughness calculation}

In general we understand as roughness the variability of a topographical surface at a given scale. A number of definitions of roughness exist; for a recent overview see Grohmann et al. (2011). We decided to choose the vector ruggedness measure developed by Sappington et al. (2007) and based on the vector approach proposed by Hobson (1972). In a preliminary step, the elevation gradient in both the $x$ and $y$ directions of a grid cell and its eight neighbouring cells is used to calculate the magnitude (slope), $\alpha$, and the direction (aspect), $\beta$, of steepest gradient (Horn, 1981). We define $a, b$ and $c$ as the upper left, upper central and upper right pixel respectively; $d$ and $f$ as the central left and central right pixel respectively; and $g, h$ and $i$ as the lower left, lower central and lower right pixel respectively (Fig. 3). We denote

$$
\begin{aligned}
& \frac{\mathrm{d} z}{\mathrm{~d} x}=\frac{(c+2 f+i)-(a+2 d+g)}{\left(8 \cdot \text { cellsize }_{x}\right)}, \\
& \frac{\mathrm{d} z}{\mathrm{~d} y}=\frac{(g+2 h+i)-(a+2 b+c)}{\left(8 \cdot \text { cellsize }_{y}\right)},
\end{aligned}
$$

where $a \ldots i$ represent the elevation of the corresponding cells and cellsize $x_{x}$ and cellsize $y$ correspond to the size of the grid cell in $x$ and $y$ direction, respectively. Slope and aspect are then calculated using the following formulas:

$$
\begin{aligned}
& \alpha=\arctan \left(\sqrt{\left(\frac{\mathrm{d} z}{\mathrm{~d} x}\right)^{2}+\left(\frac{\mathrm{d} z}{\mathrm{~d} y}\right)^{2}}\right), \\
& \beta=\arctan \left(\frac{\frac{\mathrm{d} z}{\mathrm{~d} y}}{\mathrm{~d} z}\right) .
\end{aligned}
$$

To attribute the right quadrant to the calculated aspect value, the implemented arctangent function with two input arguments allows retrieving information about the signs of the input arguments and thus returning the right quadrant. Aspect is not defined for flat areas (slope $=0^{\circ}$ ), and values are set to 


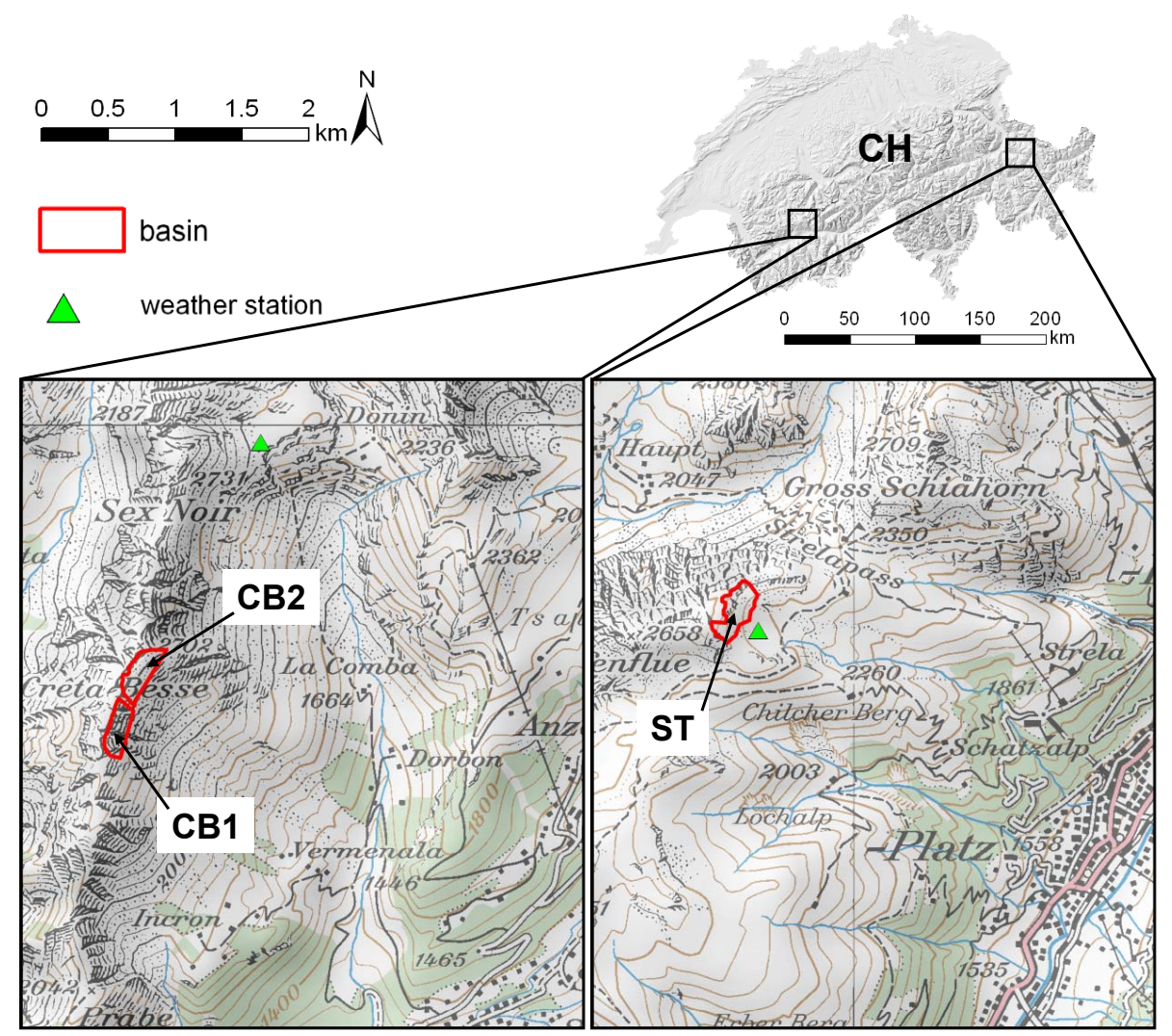

Fig. 1. Field sites Vallée de la Sionne (left) and Steintälli (right). In red are marked the exact location of the analysed basins CB1, CB2 and ST, and in green the location of the weather stations. Pixmaps ${ }^{\circledR} 2013$ swisstopo (5704 000000$)$.

-1 . Consequently, trigonometric operations using these values are treated as 0 . Based on these definitions, normal unit vectors of every grid cell of a digital elevation model (DEM) are decomposed into $x, y$ and $z$ components (Fig. 4, Eqs. 69):

$z=1 \cdot \cos (\alpha)$,

$x y=1 \cdot \sin (\alpha)$,

$x=x y \cdot \cos (\beta)$,

$y=x y \cdot \sin (\beta)$.

A resultant vector $|r|$ is then obtained for every pixel by summing up the single components of the centre pixel and its neighbours using a moving window technique. The neighbourhood size can be set by the user and is defined by the number of pixels $n$ taken into account.

$|r|=\sqrt{\left(\sum x\right)^{2}+\left(\sum y\right)^{2}+\left(\sum z\right)^{2}}$

as shown in Fig. 4b. The magnitude of the resultant vector is then normalized by the number of grid cells $n$ and subtracted from 1:

$R=1-\frac{|r|}{n}$, where $R$ is the vector ruggedness measure.

The result is a measure of the surface roughness with values ranging from 0 (flat) to 1 (extremely rough). This definition makes it possible to derive roughness directly from a DEM, and the moving window technique allows us to calculate local, pixel-based estimates of roughness. Since the method incorporates both the aspect and slope of the elevation gradient, we can distinguish between constant slope with constant aspect and constant slope with changing aspect (Fig. 4c). Sappington et al. (2007) showed that the vector ruggedness measure is uncorrelated with slope. The measure has already been applied in different research fields, including, among others, animal habitat analysis (Sappington et al., 2007), avalanche dynamics (Sovilla et al., 2012) and avalanche formation (Vontobel, 2011).

We calculated roughness for every $1 \mathrm{~m}$ grid cell of all measured winter surfaces, $R_{\mathrm{S}}$, and the corresponding summer terrain, $R_{\mathrm{T}}$. By varying the neighbourhood size from $3 \times 3$ pixels $(3 \mathrm{~m}$ scale) up to $25 \times 25$ pixels ( $25 \mathrm{~m}$ scale), we aimed to account for different scales. Scale in our context thus corresponds to the size of the moving window. 

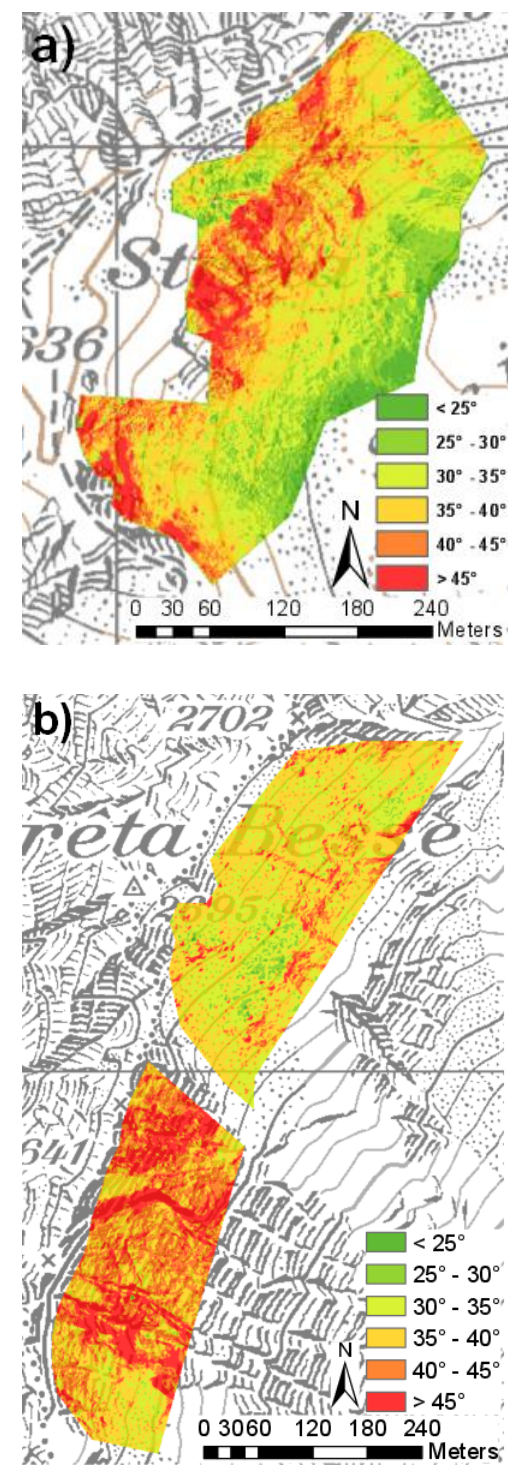

Fig. 2. Slope derived from a DTM with $1 \mathrm{~m}$ resolution in (a) the basin of ST and (b) the basin of VdlS. Pixmaps ${ }^{\circledR} 2013$ swisstopo (5704000 000).

\subsection{Terrain smoothing assessment}

Snow changes the underlying terrain by filling gullies and covering rocks; it also creates drift features such as dunes and cornices, which may be uncorrelated with the underlying terrain. Thus, to evaluate terrain smoothing it is necessary to both calculate the degree of attenuation of terrain features produced by snow and estimate the degree of similarity between winter and summer surface. In this study, we use the roughness calculations to assess the terrain smoothing processes.

To quantify terrain smoothing at basin scale, we performed a linear regression analysis between all pixels of a winter and

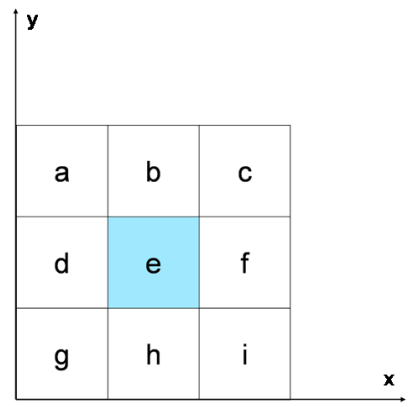

Fig. 3. Calculation of the horizontal and vertical gradient at grid cell $e$, using the elevation values of the centre cell $e$ and its eight neighbours. Gradients are calculated for each grid cell in the input raster using a $3 \times 3$ window.

the corresponding summer surface of the form

$R_{\mathrm{S}}=b \times R_{\mathrm{T}}$,

where $b$ is the slope of the regression fit. We then denote the smoothing factor $F$ :

$F=1-b$.

$F$ ranges between 0 , when surface roughness is equal to terrain roughness and no smoothing is observed, and 1 for a complete even snow surface. Theoretically, $F$ can be negative for snow surfaces which are rougher than the terrain surface.

Further, we calculate the coefficient of determination, $R^{2}$, of the regression fit, which determines the degree of similarity between the snow surface and terrain surface. High values, up to 1 , indicate that the underlying terrain is still dominating and the influence of snow is low. Low values indicate that snow influence is dominant, creating significant changes of the surface structure. Thus, these measures, $F$ and $R^{2}$ define terrain smoothing at basin scale.

At pixel scale, terrain smoothing is analysed as a function of the roughness of the summer terrain as well as of the snow depth at this position. We assume that terrain smoothing is dependent on the value of the terrain roughness under consideration. We binned terrain roughness values into classes separated by intervals of 0.002 . For each class with similar terrain roughness, snow surface roughness is analysed as a function of snow depth.

To quantify intra- and interannual persistence of snow depth and surface roughness, we calculate the degree of correlation between two distinct winter snow covers using the coefficient of determination, $R^{2}$.

\section{Results and discussion}

\subsection{Snow depth distribution}

At the Steintälli field site, eight TLS measurements were performed in three different winter seasons. Table 1 shows the 


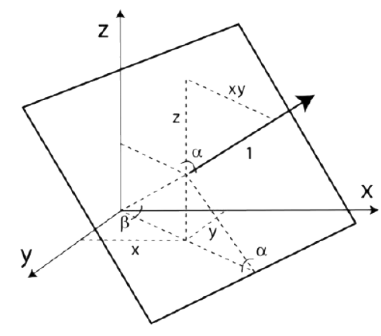

(a)

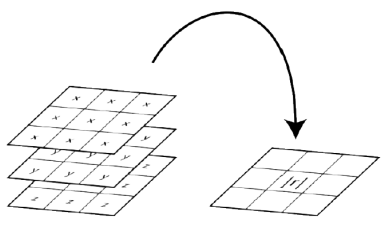

(b)

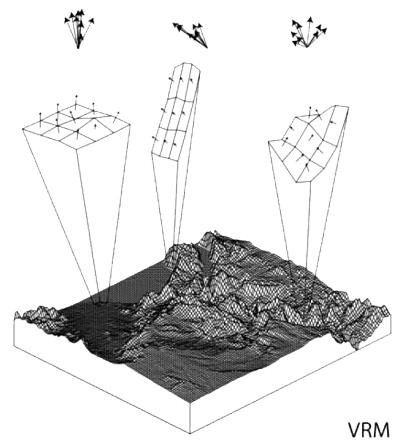

(c)

Fig. 4. Calculation of vector ruggedness measure $R$. (a) Decomposition of normal unit vectors of a DTM grid cell into $x, y$ and $z$ components using slope $\alpha$ and aspect $\beta$. (b) Resultant vector $r$ is obtained by summing up the $x, y$ and $z$ components of all pixels $n$ within the neighbourhood window. (c) Vector ruggedness measure in flat (left), steep and even (middle), as well as steep and uneven terrain (right). Graphics from Sappington et al. (2007).

Table 1. Mean $\overline{\mathrm{HS}}$, standard deviation $\sigma(\mathrm{HS})$ and coefficient of variation $C_{\mathrm{v}}$ of snow depth distribution for every laser scan acquisition in the ST basin.

\begin{tabular}{lrrr}
\hline \multicolumn{4}{c}{ Steintälli } \\
\hline Date & $\overline{\mathrm{HS}}[m]$ & $\sigma(\mathrm{HS})[m]$ & $C_{\mathrm{V}}$ \\
\hline 2 Feb 2011 & 1.33 & 0.48 & 0.36 \\
1 Mar 2011 & 1.43 & 0.53 & 0.37 \\
11 Jan 2012 & 2.75 & 0.54 & 0.20 \\
13 Feb 2012 & 1.91 & 0.60 & 0.32 \\
4 Mar 2012 & 1.99 & 0.73 & 0.36 \\
9 Mar 2012 & 2.31 & 0.70 & 0.30 \\
20 Mar 2012 & 2.01 & 0.75 & 0.37 \\
10 Jan 2013 & 1.36 & 0.35 & 0.26 \\
\hline
\end{tabular}

snow cover characteristics of all acquisitions for the basin ST. Snow depths in 2010/11 and 2012/13 were lower (between 1.33 and $1.43 \mathrm{~m}$ ) than in 2011/12, when snow depth varied between 1.91 and $2.75 \mathrm{~m}$. The coefficient of variation ranges from 0.2 to 0.37 with generally increasing values towards the end of the accumulation period. Thus we believe it is a potentially good indicator for the increasing redistribution of the snow cover during the accumulation season. Figure 5 shows the evolution of snow depth for the three winter seasons of 2010/11, 2011/12 and 2012/13 at the weather station WAN7 in close vicinity to the basin ST. Interestingly, the maximum snow depth was reached very early in the winter season 2011/2012, in January, and it is basically the result of one long period of intermittent snowfalls. Normally peak accumulations at these altitudes are reached later in the season (March or April).

At the Vallée de la Sionne test site, three ALS measurements were performed in three different winter seasons. The three scans were taken at significantly different stages of the accumulation season. Figure 5 shows the evolution of snow
Table 2. Mean $\overline{\mathrm{HS}}$, standard deviation $\sigma(\mathrm{HS})$ and coefficient of variation $C_{\mathrm{V}}$ of snow depth distribution for every laser scan acquisition in the $\mathrm{CB} 1$ and $\mathrm{CB} 2$ basins.

\begin{tabular}{lrrr}
\hline Date & $\overline{\mathrm{HS}}[m]$ & $\sigma(\mathrm{HS})[m]$ & $C_{\mathrm{V}}$ \\
\hline \multicolumn{5}{c}{ Crêta Besse 1 } \\
\hline 8 Mar 2006 & 2.71 & 0.78 & 0.29 \\
25 Jan 2009 & 1.36 & 0.64 & 0.47 \\
8 Dec 2011 & 1.39 & 0.30 & 0.22 \\
\hline \multicolumn{5}{c}{ Crêta Besse 2 } \\
\hline 8 Mar 2006 & 3.68 & 0.61 & 0.17 \\
25 Jan 2009 & 2.13 & 0.62 & 0.29 \\
8 Dec 2011 & 1.36 & 0.23 & 0.17 \\
\hline
\end{tabular}

depth for the winters 2005/06, 2008/09 and 2011/12 at the weather station Donin du Jour, which is situated about $2 \mathrm{~km}$ away from the basins. Table 2 shows the snow cover characteristics of all acquisitions for the basins CB1 and CB2. The scan acquired on 8 March 2006 can be considered close to the peak accumulation of the winter. The scan of 25 January 2009 is the result of several snowfalls within the winter season. Both scans show a significantly larger standard deviation. Finally, the scan of the 8 December 2011 was performed after the first significant snowfall of the winter season, and represents a very homogeneous snowpack where little redistribution has taken place.

We further observe that snow depth at the weather stations can significantly deviate from mean snow depth observed in the basins. Snow depth at the weather station is therefore just used for visualization purposes of the winter history. 

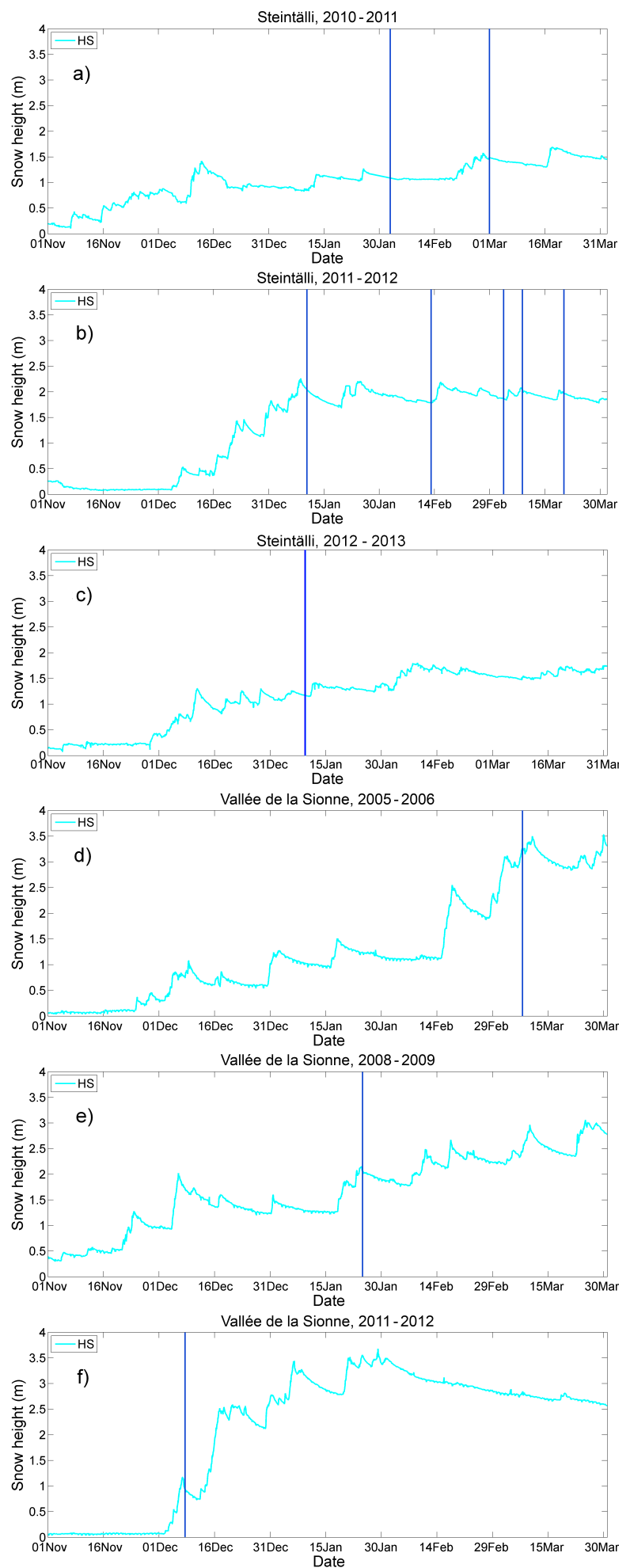

Fig. 5. Evolution of snow depth from 1 November until 31 March measured (a-c) at the weather station WAN7 in Steintälli and (d-f) at the weather station Donin du Jour in Vallée de la Sionne. The vertical blue lines correspond to the acquisition times of the laser scans.
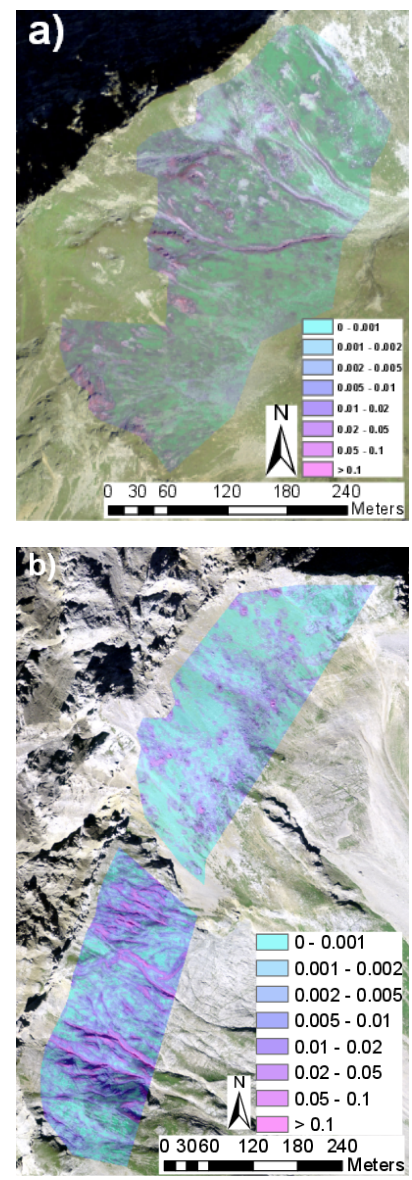

Fig. 6. Terrain roughness derived from a DTM with $1 \mathrm{~m}$ resolution, for a $5 \mathrm{~m}$ scale in (a) the ST basin and (b) the VdlS basin. Swissimage $^{\circledR} 2013$ swisstopo (5704 000 000).

\subsection{Terrain smoothing at basin scale}

Figure 6 shows terrain roughness of the three basins CB1, $\mathrm{CB} 2$ and ST. We observe that the vector ruggedness measure $R$ captures well terrain features such as rocky outcrops, boulders as well as small channels and gullies. It further confirms our selection criteria with increasing roughness from $\mathrm{CB} 2$ to $\mathrm{ST}$ to CB1. Mean roughness in CB2 is 0.0028 with a standard deviation of 0.0044 , mean roughness in ST is 0.0050 with a standard deviation of 0.0089 , and mean roughness in CB1 is 0.0084 with a standard deviation of 0.133 (all values calculated at a scale of $5 \mathrm{~m}$ ).

Figure 7 shows an example of the correlation between terrain roughness, $R_{\mathrm{T}}$, and snow surface roughness, $R_{\mathrm{S}}$, for the CB1 basin and for scales of 5 and $25 \mathrm{~m}$. We observe a linear relationship between $R_{\mathrm{S}}$ and $R_{\mathrm{T}}$. Whereas the correlation is very strong at larger scales $\left(R^{2}\right.$ of 0.97 at a scale of $25 \mathrm{~m}$ ), more deviation from the linear fit is observed on smaller scales ( $R^{2}$ of 0.73 at a scale of $5 \mathrm{~m}$ ).

Figure 8 gives an overview over all basins and shows $F$ and the coefficient of determination, $R^{2}$, of terrain roughness 

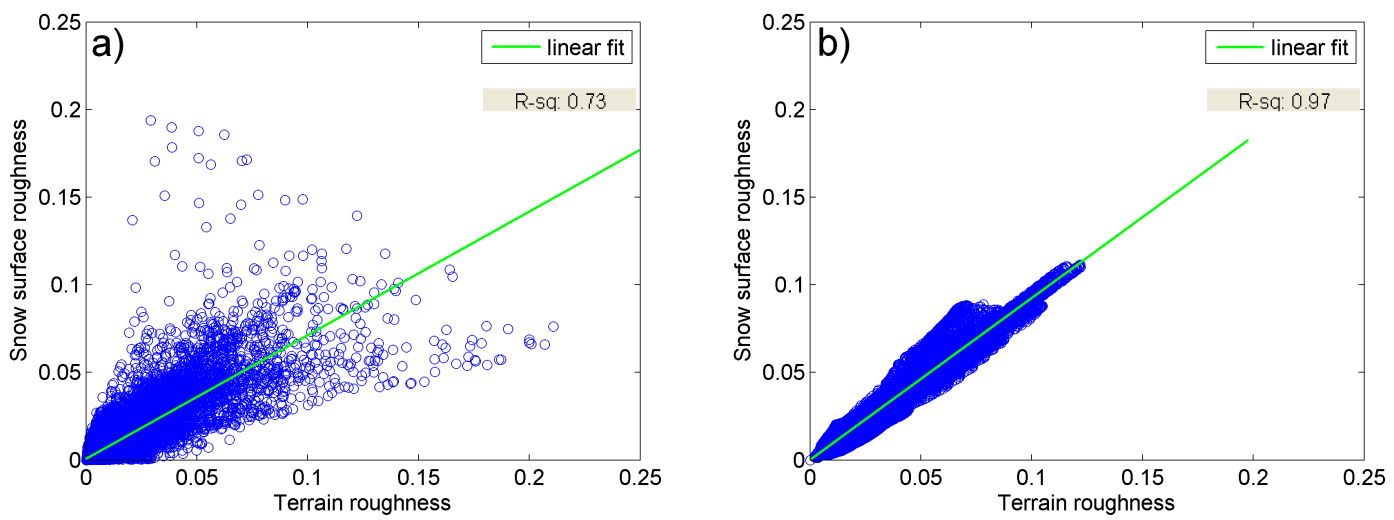

Fig. 7. Snow surface roughness as a function of terrain roughness for every pixel in CB1 in the year 2011 for scales of (a) $5 \mathrm{~m}$ and (b) $25 \mathrm{~m}$. In green the linear regression line.

and snow surface roughness as a function of different scales for the basins ST, CB1 and CB2. It confirms that correlation between terrain and surface roughness increases with scale in all basins. Further, all basins show a decreasing smoothing factor $F$ with increasing scales. Thus, we observe inversely proportional behaviour of $R^{2}$ and $F$, indicating that the more terrain roughness is attenuated (high $F$ ), the more snow surface roughness can deviate from its underlying terrain, forming a distinct winter terrain (low $R^{2}$ ). This confirms quantitatively our intuitive understanding of terrain smoothing. We further observe that terrain smoothing is generally larger (higher $F$, lower $R^{2}$ ) in sampled basins with low terrain roughness (e.g CB2, Fig. 6). Smoothing is strongest in CB2 where small-scale terrain roughness could be almost completely eliminated ( $F$ close to $1, R^{2}$ almost 0 ). With increasing terrain roughness (ST, CB1) terrain smoothing is less pronounced. This behaviour can be best illustrated with the example of 8 December 2011 in CB1 and CB2, where the first significant snowfall of the winter season resulted in a very similar mean snow depth (1.39 and $1.36 \mathrm{~m}$ in CB1 and CB2 respectively) in both basins. However, terrain smoothing is significantly larger (higher $F$, lower $R^{2}$ ) in CB2 than in CB1. This underlines that every basin has a unique imprint and shows a different smoothing behaviour even with almost identical snow depth distribution parameters such as mean snow depth.

Beside the basin characteristics, it is clear that the differences of the smoothing behaviour observed within every individual basin are due to a varying snow cover distribution.

Figure 8 shows qualitatively that terrain smoothing increases with increasing snow depth. In the basin ST for example, we clearly identify two different smoothing behaviours between the two winters of 2010/11 and 2012/13 and the winter of 2011/12, which were characterized by snow depths in the range of $1.33-1.43 \mathrm{~m}$ and $1.91-2.75 \mathrm{~m}$, respectively. This pronounced difference in snow depth of the winter season 2011/12 compared to the two others results in more pronounced smoothing at scales up to $15 \mathrm{~m}$. At larger scales, $F$ of all winter seasons converges to values of around 0.45 . However, this behaviour is not unequivocal, and mean snow depth alone cannot always explain terrain smoothing. For example, the scans of 11 January 2012 and 4 March 2012 show almost the same smoothing behaviour despite a significantly larger mean snow depth on 11 January $2012(2.75 \mathrm{~m}$ compared to $1.99 \mathrm{~m}$ on $4 \mathrm{March})$. In this case, the coefficient of variation, $C_{\mathrm{v}}$, is significantly lower for the scan of $11 \mathrm{Jan}-$ uary 2012, indicating that the snow cover is less distributed than for 4 March 2012. This is confirmed in other basins. In CB2 we observe that the smoothing in the year 2006 is only slightly larger than in 2009 despite a significantly thicker snowpack ( $3.68 \mathrm{~m}$ in 2006 compared to $2.13 \mathrm{~m}$ in 2009). Also in this case, $C_{\mathrm{v}}$ is almost twice as large in 2009, indicating that relatively more snow has been redistributed. In CB1 we observe that both years 2006 and 2009 show a very similar smoothing behaviour despite higher mean snow depth in 2006. Again, $C_{\mathrm{v}}$ is larger in 2009 ; thus the snow cover was more affected by redistribution processes.

The above observations suggest that terrain smoothing may thus be dependent on the mean snow depth, $\overline{\mathrm{HS}}$, as well as its variability, $\sigma(\mathrm{HS})$. To examine this relationship we use the data of the ST basin where eight laser scans are available. With only three scans in VdlS, this would not be possible. We define:

$\widetilde{\mathrm{HS}}=\overline{\mathrm{HS}} \times \sigma(\mathrm{HS})\left[\mathrm{m}^{2}\right]$.

Figure 9 shows $F$ with $\widetilde{\mathrm{HS}}$ for the scales of 5,15 and $25 \mathrm{~m}$ and as a comparison only with $\overline{\mathrm{HS}}$. In both cases, we can see that increasing scales lead to a decreasing smoothing behaviour and that a linear increase in $\overline{\mathrm{HS}}$ and $\widetilde{\mathrm{HS}}$ does not result in a linear increase of the smoothing factor. Therefore a power function of the form

$\widetilde{\mathrm{HS}}=c \times F^{r}$,

where $c$ and $r$ are coefficients depending on terrain characteristics and scale, describes better the exponential increase 


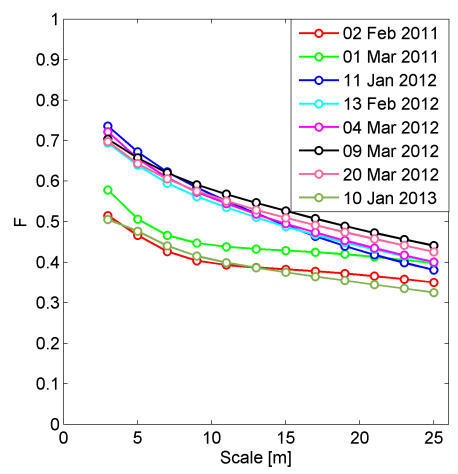

(a) $\mathrm{F}$ in $\mathrm{ST}$

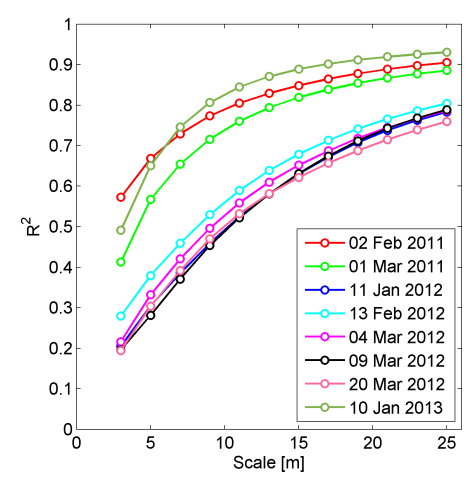

(d) $R^{2}$ in $\mathrm{ST}$

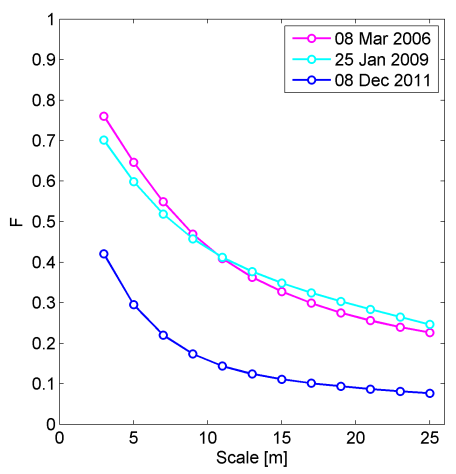

(b) $\mathrm{F}$ in $\mathrm{CB} 1$

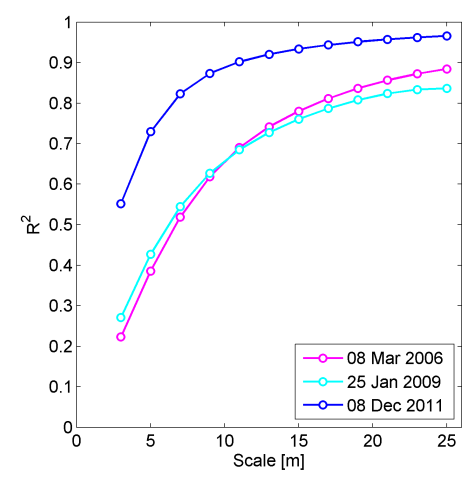

(e) $R^{2}$ in $\mathrm{CB} 1$

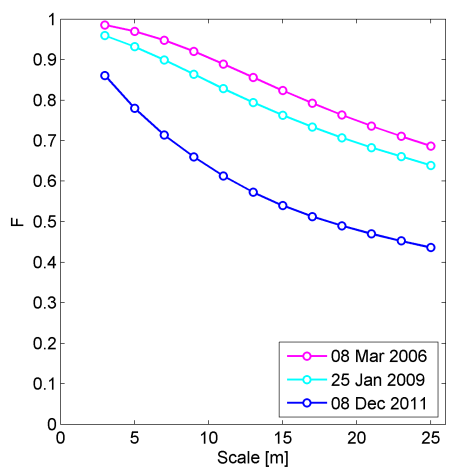

(c) $\mathrm{F}$ in $\mathrm{CB} 2$

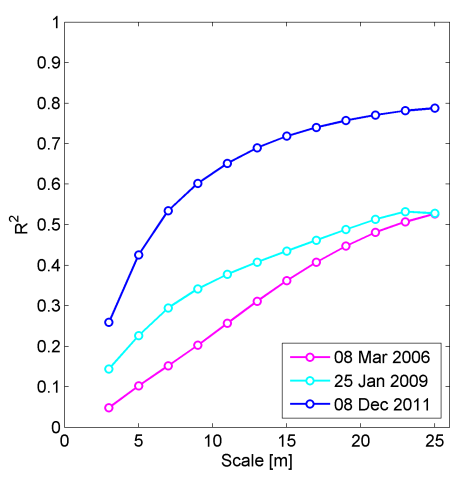

(f) $R^{2}$ in $\mathrm{CB} 2$

Fig. 8. (a-c) Smoothing factor $F$ and $(\mathbf{d}-\mathbf{f})$ coefficient of determination $R^{2}(p<0.0001)$ between snow surface roughness and terrain roughness as a function of scale for the basins ST, CB1 and CB2.

Table 3. Coefficients $c$ and $r$ of the power function modelling terrain smoothing (Eq. 16) in the basin of ST.

\begin{tabular}{lrr}
\hline & Steintälli \\
\hline Scale & $c$ & $r$ \\
\hline $5 \mathrm{~m}$ & 2.8 & 2.2 \\
$15 \mathrm{~m}$ & 10.6 & 3.2 \\
$25 \mathrm{~m}$ & 24.9 & 3.5 \\
\hline
\end{tabular}

of $\widetilde{\mathrm{HS}}$ with F. Further, by visual inspection, we observe a better agreement with the fit when the variability of snow depth is integrated.

If we solve Eq. (15) for $F$ we obtain

$F=\left(\frac{\widetilde{\mathrm{HS}}}{c}\right)^{\frac{1}{r}}$,

where Table 3 shows characteristic values of $c$ and $r$ for the basin ST.

The observed smoothing behaviour indicates that the snow which fell at the beginning of the winter season is more efficient in cancelling out roughness than larger snowfalls oc- curring later in the season, when the snow cover is already relatively high. Further, it shows how a simple standard deviation can capture complex redistribution processes such as a wind transport, at least at basin scale.

We believe that the obtained relation in this basin captures well the essence of terrain smoothing. Basins with different terrain characteristics may show different behaviours with stronger or weaker increases of $F$ in relation to snow depth and its variability.

Nonetheless, this result suggests that, in contrast to the indications given by Schweizer et al. (2003), terrain smoothing processes are not restricted to snow depths of $0.3-1 \mathrm{~m}$, but are still observable in considerably thicker snowpacks. However, it is important to emphasize that this is dependent of the scale of terrain roughness under consideration. Considering the work of Schirmer and Lehning (2011), we can confirm increasing terrain smoothing on increasing scales with a deeper and more variable snowpack; however we did not find a clear break separating scales where terrain is smoothed or not smoothed. We rather observe a gradual decrease of terrain smoothing with increasing scales.

Assuming that snow influence on terrain morphology is significant for values of $R^{2}<0.5$ between snow surface roughness and terrain roughness, we find critical scales 

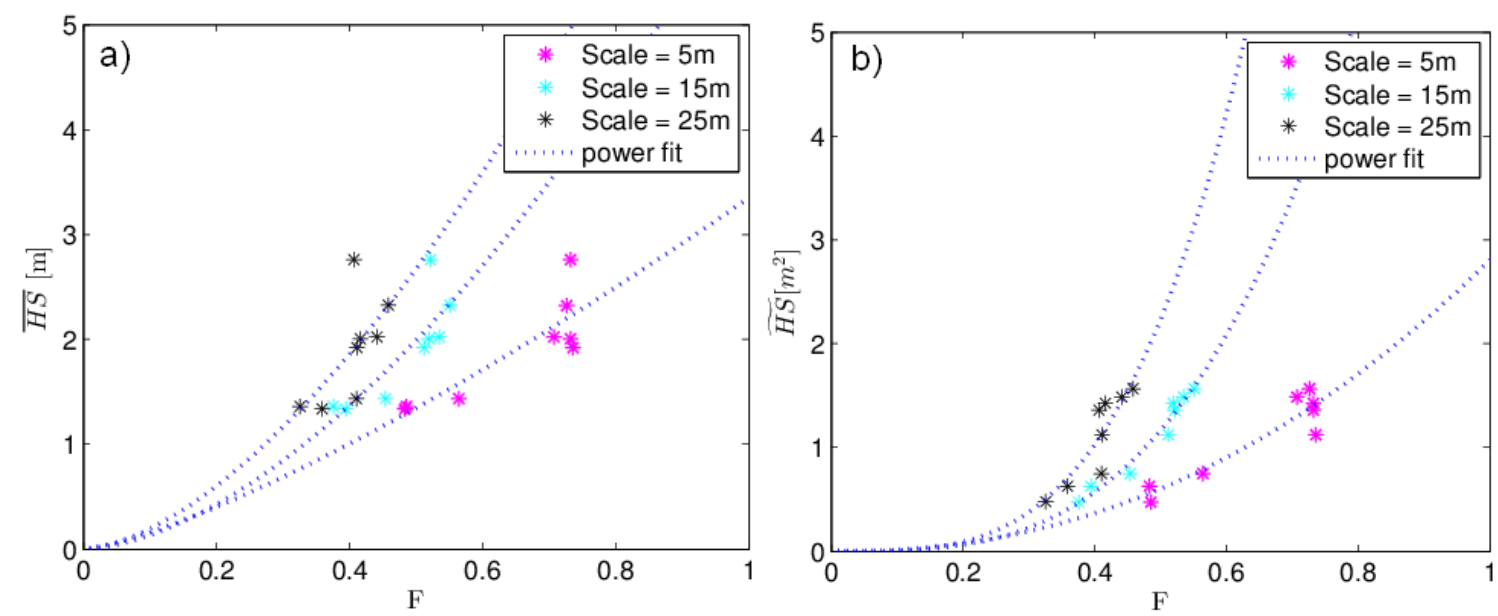

Fig. 9. (a) $F$ as a function of mean snow depth and (b) $F$ as a function of mean snow depth multiplied by its standard deviation for scales of 5,15 and $25 \mathrm{~m}$.

mostly between 5 and $10 \mathrm{~m}$ for snow depth ranging roughly between 1 and $3 \mathrm{~m}$. Larger critical scales were found in smoother terrain of CB2 with values around $25 \mathrm{~m}$. This finding is very useful to select appropriate resolutions of the DTM for modelling purposes in a winter terrain.

\subsection{Terrain smoothing at local scale}

As discussed above, terrain smoothing at basin scale is directly proportional to the average snow depth and its standard deviation. However, to understand the smoothing behaviour of single terrain features, it is necessary to assess the link between snow depth and surface roughness at local scale. Accordingly, we analysed the correlation between snow depth and terrain smoothing at pixel scale (Fig. 10). This example shows that, in contrast to what was observed at basin level, it is not possible to establish a general relationship between the two variables. No relationship was found in any basin or at any scale.

To get a deeper understanding of this behaviour, we produced gridded maps of $1 \mathrm{~m}$ resolution of snow depth and surface roughness and assessed the spatial distribution of snow depth and surface roughness. Figures 11 and 12 show two selected snow depth distributions and the corresponding surface roughness and underlying terrain roughness at a scale of 5 and $25 \mathrm{~m}$ in the basin ST and VdlS, respectively. Maps of all snow depth and roughness distributions can be consulted in the Appendix. Even if a correlation between snow depth and smoothing at the pixel level could not be found, by visual inspection we observe that snow can influence smoothing processes at feature level, systematically and persistently. This can be observed for example in Fig. 11 where channels (marked with black circles) are systematically filled with snow and completely disappear on the surface roughness maps, in all observed scans. Another example is surface roughness due to small rocks (marked with yellow

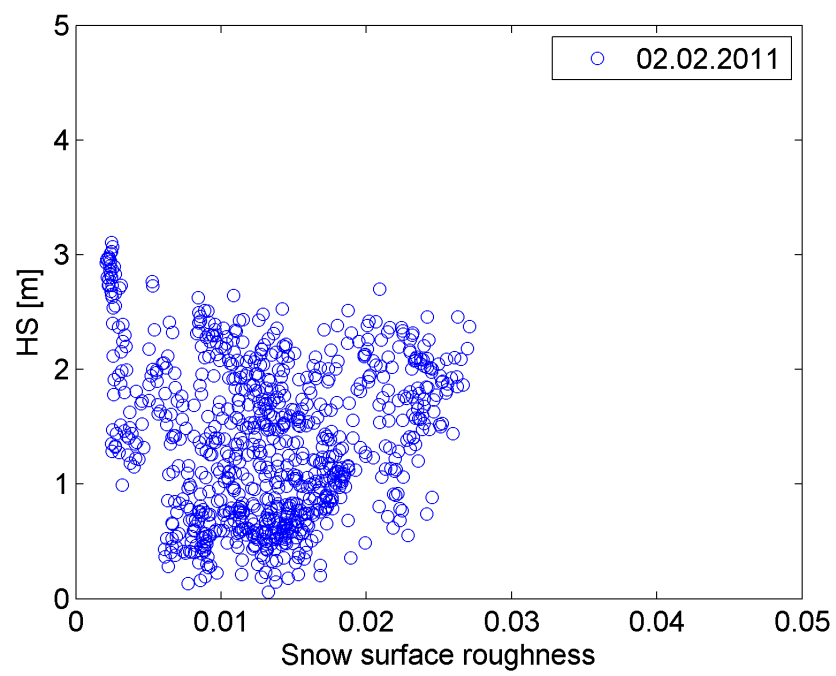

Fig. 10. Snow surface roughness as a function of snow depth for pixels with terrain roughness of $0.025 \pm 0.001$. Example for acquisition of 2 February 2011 and a scale of $15 \mathrm{~m}$ in the basin ST.

circles) which persists in all given snow cover distributions. This illustrates that smoothing processes are strongly driven by single features and explains why a local gridded representation of terrain cannot capture the complex relationship between snow depth and terrain smoothing. The smoothing of a single pixel (in our case $1 \mathrm{~m}$ ) cannot be unambiguously explained by snow depth and its terrain roughness. It is controlled by geomorphological parameters of neighbouring pixels, which control together with meteorological factors such as wind the local redistribution of snow depending on their arrangement at feature scale. Another reason is that terrain smoothing may vary strongly within an individual basin due to local wind conditions and their interaction with the underlying terrain features, which strongly influence 
Table 4. Coefficient of determination $\left(R^{2}\right)$ of correlations between snow depth distributions in the CB1 and CB2 basins $(p<0.0001)$.

\begin{tabular}{lrrr}
\hline Date & 8 Mar 2006 & 25 Jan 2009 & 8 Dec 2011 \\
\hline & Crêta Besse 1 & & \\
\hline 8 Mar 2006 & 1 & 1 & \\
25 Jan 2009 & 0.73 & 0.34 & 1 \\
8 Dec 2011 & 0.41 & & \\
\hline \multicolumn{5}{c}{ Crêta Besse 2 } & 1 & \\
\hline 8 Mar 2006 & 1 & 0.29 & 1 \\
25 Jan 2009 & 0.58 & & \\
8 Dec 2011 & 0.54 & & \\
\hline
\end{tabular}

deposition, redistribution (e.g. snow drift, saltation, preferential deposition (Lehning et al., 2008; Mott et al., 2010)) and/or wind erosion processes. Surface roughness might thus be influenced by drift features (dunes, cornices) or sastrugi. This complex behaviour is not captured by a simple power law as shown in Sect. 3.2, but can only be reproduced using physical models able to calculate snow redistribution in 3-D terrain (e.g. Alpine 3-D; Lehning et al., 2006).

However we stress that, under snow influence, characteristic patterns of surface roughness appear to be persistent. In the following we will thus analyse quantitatively the persistence of snow depth distribution and whether persistence is further transferred to surface roughness.

\subsection{Intra- and interannual persistence of snow depth}

Table 5 shows the correlations of the snow depth distribution for the Steintälli basin. We observe high intra-annual correlation of 0.81 between the two scans in the season 2010/11 as well as the last four scans in 2011/12, with values ranging from 0.73 to 0.93 . Only the scan from 11 January 2012 is correlated to a less strong extent with all other scans from this winter season, with values ranging from 0.43 to 0.58 . Thus, in general the intra-annual correlation at this site is strong, with higher values towards the middle and end of the accumulation season.

The same holds for the interannual comparison. The correlation between scans performed at the beginning of the winter season is generally lower as in the case of the scan from 11 January 2012 compared with the scan from 2 February $2011\left(R^{2}=0.25\right)$ and with that from 10 January 2013 $\left(R^{2}=0.28\right)$. The correlation increases for scans performed towards the end of the winter season as in the case of scans from 1 March 2011 and 20 March $2012\left(R^{2}=0.65\right)$. Still, we observe that strong correlations exist also between scans acquired substantially before the peak of the accumulation season (e.g. scans of 10 January 2013 and 2 February 2011 with a correlation of $R^{2}=0.69$ ).
Table 4 shows correlations of the snow depth distribution for the basins CB1 and CB2. In this case we can only perform an interannual comparison, and in agreement with the results from the Steintälli basin the correlation increases for scans which correspond to the end of the accumulation season. In fact, we can observe that in basin CB1 the years 2006 and 2009 are more highly correlated $\left(R^{2}=0.73\right)$ than 2006 and 2009 with $2011\left(R^{2}=0.41\right.$ and $R^{2}=0.34$, respectively $)$. In CB2 this effect is less pronounced, which can be explained by the fact that smooth terrain generally shows lower interannual persistence $\left(R^{2}=0.58\right.$ between 2006 and 2009).

To summarize, we generally observe larger intra- and interannual persistence for snow depth distributions acquired closer to the end of the accumulation period which have been exposed to settling and redistribution processes over a whole winter. Still, large persistence is possible already early in the accumulation season, under the condition that a certain settling and redistribution has occurred (e.g. scans of 10 January 2013 and 2 February 2011 in ST). A significantly weaker intra- and interannual consistency was observed for snow depth distributions which resulted basically from the first snowfall or snowfall period in the winter season, like the scans from 11 January 2012 in ST or the scan from 8 December 2011 in VdlS. Thus, a single snowfall (period) at the beginning of the accumulation season can considerably vary from the characteristic accumulation pattern.

This is in agreement with previous studies of the snow cover distribution, which have generally found very high interannual persistence of the snow cover at the end of the accumulation season, with correlations up to 0.97 (Pearson's correlation coefficient; Schirmer et al., 2011). Yet, interannual persistence is slightly lower in the Steintälli basin. This can be explained by large glide cracks in the winter season 2011/12, affecting the snow depth distribution during the whole winter season. Still the correlations are significant and the results confirm the hypothesis that the snow cover distribution converges towards a site-specific, characteristic pattern.

\subsection{Intra- and interannual persistence of surface roughness}

Tables 6 and 7 show the correlation of surface roughness of all winter surfaces with each other and with terrain roughness at scales of 5, 15 and $25 \mathrm{~m}$ for the basins ST, CB1 and CB2 respectively.

Generally we observe that the correlations between summer and winter terrain roughness and between the different winter surfaces increase with larger scales. This can be explained by the fact that at larger scales the snow surface more closely follows terrain. Further, winter surfaces with a thinner snowpack are more strongly correlated with the terrain than winter surfaces consisting of a thick snowpack (e.g. scans of 2010/11 and 2012/13 compared to 2011/12 in ST). 


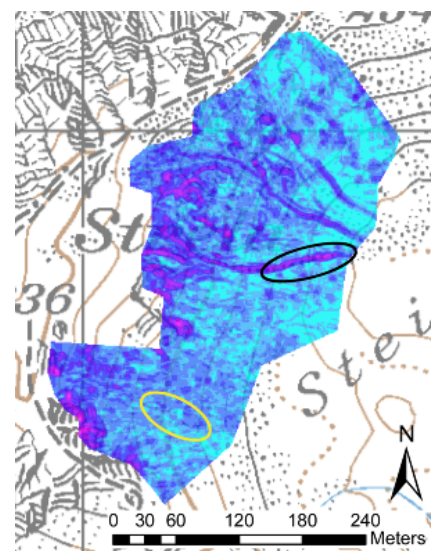

(a) DTM

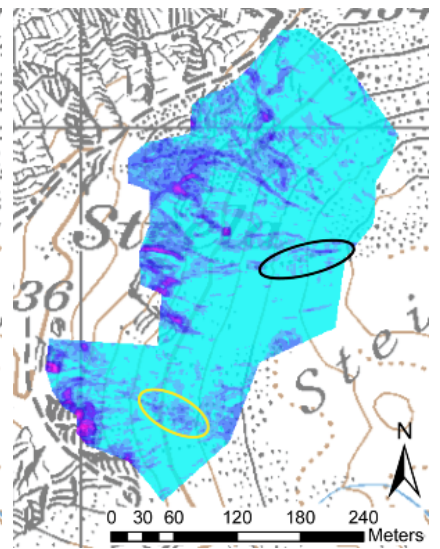

(b) 01 Mar 2011

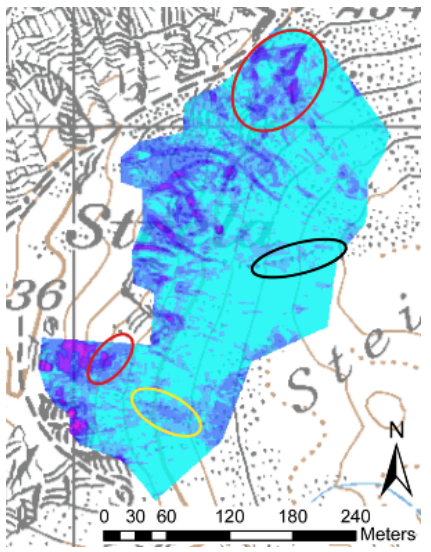

(c) 20 Mar 2012

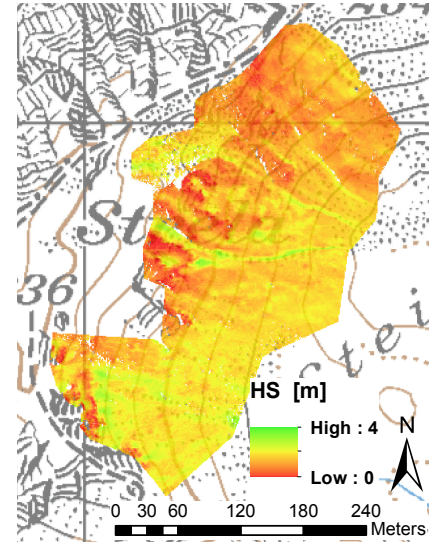

(d) 01 Mar 2011

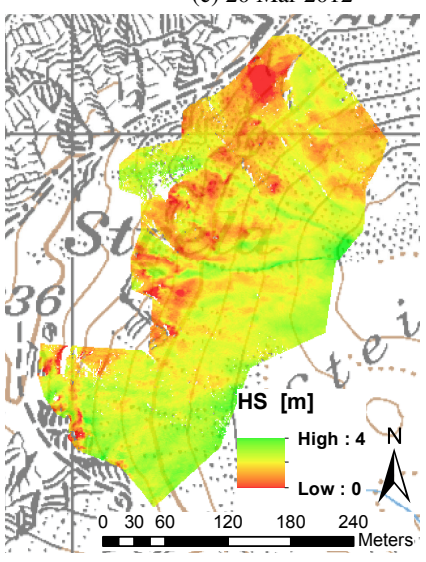

(e) 20 Mar 2012

Fig. 11. (a) Surface roughness of summer terrain and (b, c) winter terrain at a scale of $5 \mathrm{~m}$ in the basin ST. (d, e) show the corresponding snow depth distributions. The black and yellow circles show persistent smoothing features. Red circles show the location of glide cracks. Pixmaps ${ }^{\circledR} 2013$ swisstopo (5704 000 000).

Table 5. Coefficient of determination $\left(R^{2}\right)$ of correlations between snow depth distributions in the ST basin $(p<0.0001)$.

\begin{tabular}{|c|c|c|c|c|c|c|c|c|}
\hline \multicolumn{9}{|c|}{ Steintälli } \\
\hline Date & 2 Feb 2011 & 1 Mar 2011 & 11 Jan 2012 & 13 Feb 2012 & 4 Mar 2012 & 9 Mar 2012 & 20 Mar 2012 & 10 Jan 2013 \\
\hline 2 Feb 2011 & 1 & & & & & & & \\
\hline 1 Mar 2011 & 0.81 & 1 & & & & & & \\
\hline 11 Jan 2012 & 0.25 & 0.30 & 1 & & & & & \\
\hline 13 Feb 2012 & 0.37 & 0.51 & 0.58 & 1 & & & & \\
\hline 4 Mar 2012 & 0.53 & 0.64 & 0.44 & 0.81 & & & & \\
\hline 9 Mar 2012 & 0.54 & 0.57 & 0.52 & 0.79 & 0.86 & 1 & & \\
\hline 20 Mar 2012 & 0.61 & 0.63 & 0.43 & 0.73 & 0.91 & 0.93 & 1 & \\
\hline 10 Jan 2013 & 0.69 & 0.59 & 0.28 & 0.34 & 0.41 & 0.50 & 0.49 & 1 \\
\hline
\end{tabular}

We observe that the persistence of snow surface roughness follows similar patterns to those observed for the snow depth distribution. For example, the intra-annual persistence at a scale of $5 \mathrm{~m}$ in ST in 2010/11 is slightly larger than those of the corresponding snow depth distribution $\left(R^{2}=0.89\right.$ compared to 0.81 for snow depth), whereas in 2011/12 the persistence is slightly weaker. The same is observed for the interan- nual persistence. If we take as a reference the scan of $10 \mathrm{Jan}$ uary 2013, interannual persistence is higher when compared with the scans of 2010/11 and lower when compared with the scans towards the end of winter season 2011/12. This can be explained with the increasing formation of glide snow cracks leading to substantial alterations of the snow surface (marked with red circles in Fig. 11). Whereas persistence of snow 


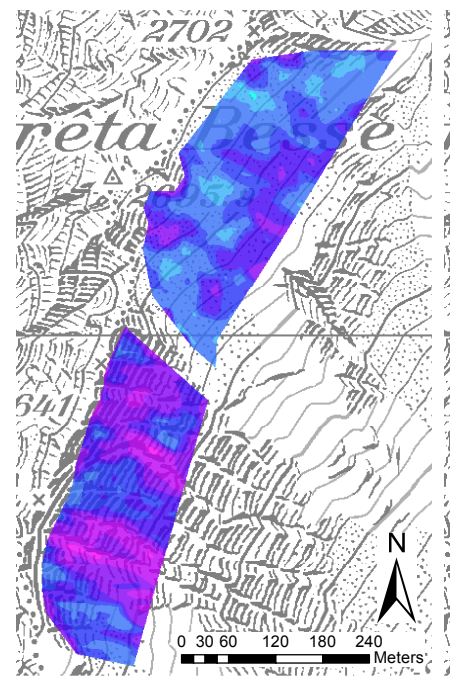

(a) DTM

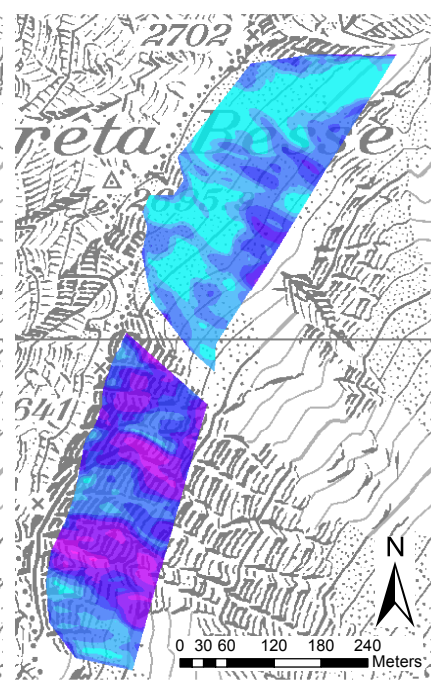

(b) 08 Mar 2006

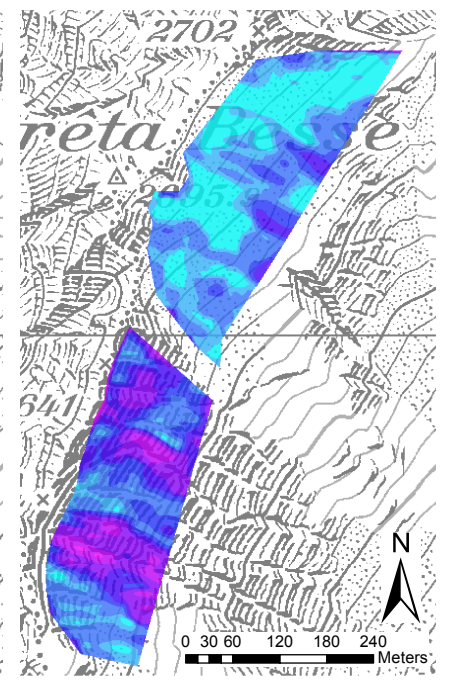

(c) 25 Jan 2009

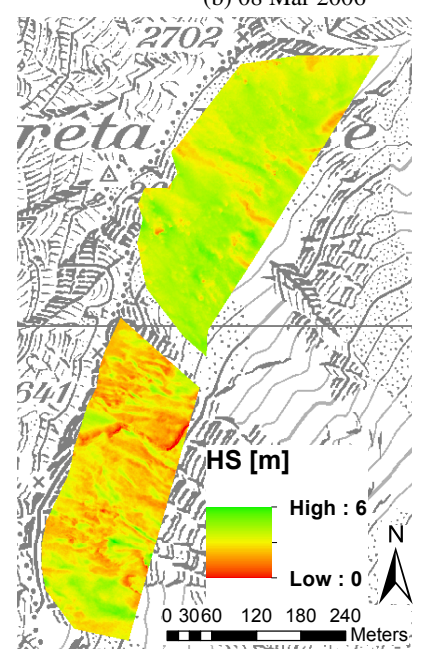

(d) 08 Mar 2006

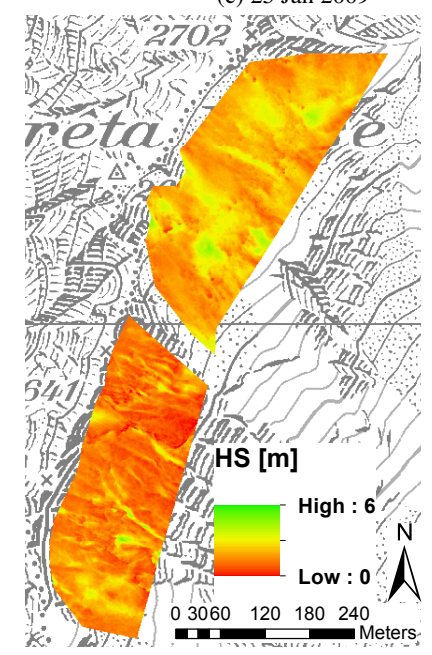

(e) 25 Jan 2009

Fig. 12. (a) Surface roughness of summer terrain and (b, c) winter terrain at a scale of $25 \mathrm{~m}$ in the basins CB1 and CB2. (d, e) show the corresponding snow depth distributions. Pixmaps ${ }^{\circledR} 2013$ swisstopo (5704 000 000).

surface roughness is similar to those of the snow depth distribution at a scale of $5 \mathrm{~m}$, it is significantly higher for the larger scales of 15 and $25 \mathrm{~m}$. Even more important, winter terrain roughness is correlated to a significantly larger degree with all other winter surfaces with similar or larger snow depth than each of the winter surfaces is with the terrain. For example, at a scale of $5 \mathrm{~m}$ in ST, an increase of $R^{2}$ between 0.09 and 0.16 for all winter surfaces is observed using the winter terrain of 10 January 2013 as a reference instead of the summer terrain. This is noteworthy as several glide cracks in winter 2011/12 introduced considerable alteration in the surfaces. At larger scales of 15 and $25 \mathrm{~m}$ the increase is also observed but to a slightly lesser extent. This is mainly due to the already very strong correlation with the terrain at larger scales, reducing the potential gain in correlation.
The same behaviour can be observed in the basins CB1 and CB2. Using for example the scan of the first snowfall of the winter season on 8 December 2011 instead of the summer terrain increases the correlation with the surfaces of 8 March 2006 and 25 January 2009 of 0.1 and 0.23 respectively in CB1 (0.21 and 0.1 in CB2 respectively). In the case of CB2 the increase of correlation is even more pronounced on larger scales $(15$ and $25 \mathrm{~m})$ than at the $5 \mathrm{~m}$ scale, with an increase of $R^{2}$ up to 0.31 . That confirms the finding in Sect. 3.3 that snow influence in smooth terrain affects larger scales than in rough terrain.

Overall, this finding is important in the sense that, at scales where snow has a significant influence on terrain morphology, a DSM of a snow surface explains to some extent the variance between snow surface roughness and terrain roughness. It might be thus possible to capture the persistent 
Table 6. Coefficient of determination $\left(R^{2}\right)$ of surface roughness correlations in the ST basin $(p<0.0001)$.

\begin{tabular}{|c|c|c|c|c|c|c|c|c|c|c|}
\hline \multicolumn{11}{|c|}{ Steintälli } \\
\hline Scale & Date & 2 Feb 2011 & 1 Mar 2011 & 11 Jan 2012 & 13 Feb 2012 & 4 Mar 2012 & 9 Mar 2012 & 20 Mar 2012 & 10 Jan 2013 & DTM \\
\hline $5 \mathrm{~m}$ & 2 Feb 2011 & 1 & & & & & & & & \\
\hline $5 \mathrm{~m}$ & 1 Mar 2011 & 0.89 & 1.00 & & & & & & & \\
\hline $5 \mathrm{~m}$ & 11 Jan 2012 & 0.43 & 0.42 & 1 & & & & & & \\
\hline $5 \mathrm{~m}$ & 13 Feb 2012 & 0.51 & 0.50 & 0.49 & 1 & & & & & \\
\hline $5 \mathrm{~m}$ & 4 Mar 2012 & 0.48 & 0.50 & 0.51 & 0.69 & & & & & \\
\hline $5 \mathrm{~m}$ & 9 Mar 2012 & 0.41 & 0.38 & 0.41 & 0.53 & 0.80 & 1 & & & \\
\hline $5 \mathrm{~m}$ & 20 Mar 2012 & 0.45 & 0.47 & 0.40 & 0.52 & 0.79 & 0.77 & 1 & & \\
\hline $5 \mathrm{~m}$ & 10 Jan 2013 & 0.78 & 0.73 & 0.44 & 0.51 & 0.44 & 0.38 & 0.41 & 1 & \\
\hline $5 \mathrm{~m}$ & DTM & 0.67 & 0.57 & 0.30 & 0.38 & 0.33 & 0.28 & 0.30 & 0.65 & 1 \\
\hline $15 \mathrm{~m}$ & 2 Feb 2011 & 1 & & & & & & & & \\
\hline $15 \mathrm{~m}$ & 1 Mar 2011 & 0.98 & 1.00 & & & & & & & \\
\hline $15 \mathrm{~m}$ & 11 Jan 2012 & 0.66 & 0.65 & 1 & & & & & & \\
\hline $15 \mathrm{~m}$ & $13 \mathrm{Feb} 2012$ & 0.70 & 0.68 & 0.77 & 1 & & & & & \\
\hline $15 \mathrm{~m}$ & 4 Mar 2012 & 0.68 & 0.67 & 0.80 & 0.88 & & & & & \\
\hline $15 \mathrm{~m}$ & 9 Mar 2012 & 0.68 & 0.67 & 0.74 & 0.80 & 0.96 & 1 & & & \\
\hline $15 \mathrm{~m}$ & 20 Mar 2012 & 0.67 & 0.67 & 0.72 & 0.77 & 0.94 & 0.97 & 1 & & \\
\hline $15 \mathrm{~m}$ & 10 Jan 2013 & 0.94 & 0.93 & 0.75 & 0.75 & 0.74 & 0.72 & 0.70 & 1 & \\
\hline $15 \mathrm{~m}$ & DTM & 0.85 & 0.82 & 0.63 & 0.68 & 0.65 & 0.63 & 0.62 & 0.89 & 1 \\
\hline $25 \mathrm{~m}$ & 2 Feb 2011 & 1 & & & & & & & & \\
\hline $25 \mathrm{~m}$ & 1 Mar 2011 & 0.99 & 1.00 & & & & & & & \\
\hline $25 \mathrm{~m}$ & 11 Jan 2012 & 0.81 & 0.80 & 1 & & & & & & \\
\hline $25 \mathrm{~m}$ & 13 Feb 2012 & 0.80 & 0.79 & 0.89 & 1 & & & & & \\
\hline $25 \mathrm{~m}$ & 4 Mar 2012 & 0.80 & 0.79 & 0.91 & 0.94 & & & & & \\
\hline $25 \mathrm{~m}$ & 9 Mar 2012 & 0.83 & 0.82 & 0.90 & 0.92 & 0.98 & 1 & & & \\
\hline $25 \mathrm{~m}$ & 20 Mar 2012 & 0.79 & 0.79 & 0.86 & 0.88 & 0.97 & 0.99 & 1 & & \\
\hline $25 \mathrm{~m}$ & 10 Jan 2013 & 0.97 & 0.96 & 0.87 & 0.85 & 0.85 & 0.87 & 0.82 & 1 & \\
\hline $25 \mathrm{~m}$ & DTM & 0.91 & 0.89 & 0.78 & 0.80 & 0.79 & 0.79 & 0.76 & 0.93 & 1 \\
\hline
\end{tabular}

Table 7. Coefficient of determination $\left(R^{2}\right)$ of surface roughness correlations in the CB1 and CB2 basins $(p<0.0001)$.

\begin{tabular}{|c|c|c|c|c|c|c|c|c|c|}
\hline \multirow[b]{2}{*}{ Scale } & \multicolumn{5}{|c|}{ Crêta Besse 1} & \multicolumn{4}{|c|}{ Crêta Besse 2} \\
\hline & Date & 8 Mar 2006 & 25 Jan 2009 & 8 Dec 2011 & DTM & 8 Mar 2006 & 25 Jan 2009 & 8 Dec 2011 & DTM \\
\hline $5 \mathrm{~m}$ & 8 Mar 2006 & 1 & & & & 1 & & & \\
\hline $5 \mathrm{~m}$ & 25 Jan 2009 & 0.62 & 1 & & & 0.38 & 1 & & \\
\hline $5 \mathrm{~m}$ & 8 Dec 2011 & 0.49 & 0.65 & 1 & & 0.31 & 0.33 & 1 & \\
\hline $5 \mathrm{~m}$ & DTM & 0.39 & 0.43 & 0.73 & 1 & 0.10 & 0.23 & 0.43 & 1 \\
\hline $15 \mathrm{~m}$ & 8 Mar 2006 & 1 & & & & 1 & & & \\
\hline $15 \mathrm{~m}$ & 25 Jan 2009 & 0.89 & 1 & & & 0.74 & 1 & & \\
\hline $15 \mathrm{~m}$ & 8 Dec 2011 & 0.84 & 0.84 & 1 & & 0.67 & 0.64 & 1 & \\
\hline $15 \mathrm{~m}$ & DTM & 0.78 & 0.76 & 0.93 & 1 & 0.36 & 0.43 & 0.72 & 1 \\
\hline $25 \mathrm{~m}$ & 8 Mar 2006 & 1 & & & & 1 & & & \\
\hline $25 \mathrm{~m}$ & 25 Jan 2009 & 0.95 & 1 & & & 0.83 & 1 & & \\
\hline $25 \mathrm{~m}$ & 8 Dec 2011 & 0.92 & 0.89 & 1 & & 0.81 & 0.74 & 1 & \\
\hline $25 \mathrm{~m}$ & DTM & 0.88 & 0.84 & 0.97 & 1 & 0.53 & 0.53 & 0.79 & 1 \\
\hline
\end{tabular}

characteristics of a winter terrain surface, including wind effects, without extensive modelling of the snow cover. However, this is only true if the reference DSM is used to approximate winter surfaces with similar or deeper snowpack. A DSM representing a very thick snow cover situation might be less representative for a thin snow cover situation than the summer DTM.
Moreover, the observed patterns of homogenous snow surface roughness, especially at larger scales $(>10 \mathrm{~m})$, appear to be well suited to defining potential avalanche release areas. We observed that these patterns are generally strongly persistent for different snow depth distributions; however they still diverge locally in some regions. Whereas the persistent parts may represent the zone where an avalanche most often releases, the changes (e.g. connection of two areas with low 
surface roughness, Fig. 12) may explain to some extent the regularly observed differences in release area size and location. This is supported by recent mechanically based, statistical modelling of the slab-weak-layer system, which emphasizes the important role of small changes in terrain morphology in the definition of release area size (Gaume, 2012).

\section{Conclusions}

In this study we present a method to quantify terrain smoothing based on a multi-scale roughness approach. This method allows us to link terrain smoothing to geomorphological parameters as the roughness estimates used in our study are based on changes in slope and aspect. Together with the possibility to precisely map roughness changes in the terrain, this is a significant step forward in interpreting terrain smoothing.

The analysis of three selected alpine basins suggests that, at basin scale, not only mean snow depth but also its variability drive the process of terrain smoothing. The multitemporal analysis in one basin revealed that the relation between terrain smoothing and snow depth parameters follows a power law indicating that snowfalls at the beginning of the winter season are more efficient in eliminating terrain roughness than snowfalls occurring later in the season. On the other hand, a relationship between terrain smoothing and snow depth was not found at pixel level as geomorphology and snow depth of neighbouring pixels strongly influence surface roughness at a given point. Still, at larger scales, winter terrain roughness can be derived, even at pixel level, from a summer DTM using a simple smoothing factor as the relationship between terrain and snow surface roughness is strongly linear. At smaller scales, snow surface roughness decorrelates stronger from terrain roughness and the summer DTM is not representative for the winter surface anymore. In this case, the representation of a winter terrain can be significantly improved by the acquisition of a winter DSM with similar or less snow depth as it captures site-specific and persistent effects of wind-terrain interaction on the snow depth distribution.

Our results are promising; however, the relatively small number of data sets with limited spatial and temporal extent restricts the generality of our results. A larger number of scans obtained in all possible snow cover situations, covering different terrain types and snow climates, would be necessary to confirm and strengthen the significance of our findings. New technologies to derive high-resolution DSMs over a wide area even in a winter terrain are currently being developed (Bühler et al., 2012; Bühler, 2012), making it more feasible in the future to obtain DSMs at significantly lower cost than lidar techniques.

Such winter terrains may then be very useful in avalanche dynamics simulations (e.g. RAMMS; Christen et al., 2010) as they provide a more realistic estimation of topography. For example the disappearance of small channels observed in a winter terrain can have a large influence on the main direction taken by the flow in 2-D or 3-D simulations (Maggioni et al., 2013). Further, the estimation of friction parameters could also be significantly improved. Moreover, the persistent patterns of winter surface roughness appear to be well suited to defining potential avalanche release areas and, thus, to improving automatic procedures for avalanche release area detection (Maggioni and Gruber, 2003; Bühler et al., 2013) and consequently natural hazard management strategies. Still, it remains unclear which scales are critical for the processes determining avalanche release size and location. This has to be assessed in future studies. A more realistic winter terrain will further improve modelling of wind-ground interaction in snow-covered terrain and be important for better snow redistribution simulation, which can be valuable for water resources assessment or ecology purposes.

Acknowledgements. Funding for this research has been provided through the Interreg project STRADA by the following partners: Amt für Wald Graubünden, Canton du Valais - Service de forêts et paysage, Regione Lombardia, ARPA Lombardia, ARPA Piemonte, and Regione Autonoma Valle d'Aosta. The authors would like to thank Walter Steinkogler for helping in the acquisition of the laser scans. We also thank the two reviewers, Margherita Maggioni and Samuel Morin, for their very constructive comments and corrections which considerably improved the manuscript.

Edited by: E. Larour

\section{References}

Blöschl, G.: Scaling issues in snow hydrology, Hydrol. Process., 13, 2149-2175, 1999.

Bühler, Y.: Remote sensing tools for snow and avalanche research, Proceedings of the 2012 International Snow Science Workshop, Anchorage, Alaska, 264-268, 2012.

Bühler, Y., Marty, M., and Ginzler, C.: High Resolution DEM Generation in High-Alpine Terrain Using Airborne Remote Sensing Techniques, Transactions in GIS, 16, 635-647, 2012.

Bühler, Y., Kumar, S., Veitinger, J., Christen, M., Stoffel, A., and Snehmani: Automated identification of potential snow avalanche release areas based on digital elevation models, Nat. Hazards Earth Syst. Sci., 13, 1321-1335, doi:10.5194/nhess-13-13212013, 2013.

Christen, M., Kowalski, J., and Bartelt, P.: RAMMS: Numerical simulation of dense snow avalanches in three-dimensional terrain, Cold Reg. Sci. Technol., 63, 1-14, 2010.

Deems, J. S., Fassnacht, S. R., and Elder, K. J.: Fractal Distribution of Snow Depth from Lidar Data, J. Hydrometeorol., 7, 285-297, 2006.

Deems, J. S., Fassnacht, S. R., and Elder, K. J.: Interannual Consistency in Fractal Snow Depth Patterns at Two Colorado Mountain Sites, J. Hydrometeorol., 9, 977-988, 2008.

Fassnacht, S., Williams, M., and Corrao, M.: Changes in the surface roughness of snow from millimetre to metre scales, Ecol. Complex., 6, 221-229, 2009. 
Fischer, L., Eisenbeiss, H., Kääb, A., Huggel, C., and Haeberli, W.: Monitoring topographic changes in a periglacial high-mountain face using high-resolution DTMs, Monte Rosa East Face, Italian Alps, Permafrost Periglac., 22, 140-152, 2011.

Gaume, J.: Evaluation of avalanche release depths. Combined statistical mechanical modeling, Ph.D. thesis, Universit é de Grenoble, 2012.

Grohmann, C., Smith, M., and Riccomini, C.: Multiscale Analysis of Topographic Surface Roughness in the Midland Valley, Scotland, IEEE T. Geosci. Remote, 49, 1200-1213, 2011.

Grünewald, T., Schirmer, M., Mott, R., and Lehning, M.: Spatial and temporal variability of snow depth and ablation rates in a small mountain catchment, The Cryosphere, 4, 215-225, doi:10.5194/tc-4-215-2010, 2010.

Grünewald, T., Stötter, J., Pomeroy, J. W., Dadic, R., Moreno Baños, I., Marturià, J., Spross, M., Hopkinson, C., Burlando, P., and Lehning, M.: Statistical modelling of the snow depth distribution in open alpine terrain, Hydrol. Earth Syst. Sci., 17, 3005-3021, doi:10.5194/hess-17-3005-2013, 2013.

Hobson, R. D.: Surface roughness in topography: a quantitative approach, 221-245, Harper \& Row, 1972.

Horn, B. K. P.: Hill shading and the reflectance map, P. IEEE, 69, 14-47, 1981.

Lehning, M., Völksch, I., Gustafsson, D., Nguyen, T. A., Stähli, M., and Zappa, M.: ALPINE3D: a detailed model of mountain surface processes and its application to snow hydrology, Hydrol. Process., 20, 2111-2128, 2006.

Lehning, M., Löwe, H., Ryser, M., and Raderschall, N.: Inhomogeneous precipitation distribution and snow transport in steep terrain, Water Res. Res., 44, W07404, doi:10.1029/2007WR006545, 2008.

Lehning, M., Grünewald, T., and Schirmer, M.: Mountain snow distribution governed by an altitudinal gradient and terrain roughness, Geophys. Res. Lett., 38, L19504, doi:10.1029/2011GL048927, 2011.

Maggioni, M. and Gruber, U.: The influence of topographic parameters on avalanche release dimension and frequency, Cold Reg. Sci. Technol., 37, 407-419, 2003.

Maggioni, M., Bovet, E., Dreier, L., Buehler, Y., Godone, D., Bartelt, P., M., F., Chiaia, B., and Segor, V.: Influence of summer and winter surface topography on numerical avalanche simulations, Proceedings of the 2013 International Snow Science Workshop, Grenoble, France, 591-598, 2013.

Manninen, T., Anttila, K., Karjalainen, T., and Lahtinen, P.: Automatic snow surface roughness estimation using digital photos, $\mathrm{J}$. Glaciol., 58, 993-1007, 2012.

McClung, D.: Characteristics of terrain, snow supply and forest cover for avalanche initiation caused by logging, Ann. Glaciol., 32, 223-229, 2001.

McClung, D. M. and Schaerer, P. A.: The Avalanche Handbook, Seattle, WA, the mountaineers Edn., 2002.

Mott, R., Schirmer, M., Bavay, M., Grünewald, T., and Lehning, M.: Understanding snow-transport processes shaping the mountain snow-cover, The Cryosphere, 4, 545-559, doi:10.5194/tc-4-5452010,2010
Prokop, A.: Assessing the applicability of terrestrial laser scanning for spatial snow depth measurements, Cold Reg. Sci. Technol., 54, 155-163, 2008.

Prokop, A., Schirmer, M., Rub, M., Lehning, M., and Stocker, M.: A comparison of measurement methods: terrestrial laser scanning, tachymetry and snow probing for the determination of the spatial snow-depth distribution on slopes, Ann. Glaciol., 49, 210-216, 2008.

Sappington, J., Longshore, K., and Thomson, D.: Quantifiying Landscape Ruggedness for Animal Habitat Anaysis: A case Study Using Bighorn Sheep in the Mojave Desert, J. Wildlife Manage., 71, 1419-1426, 2007.

Schirmer, M. and Lehning, M.: Persistence in intra-annual snow depth distribution: 2. Fractal analysis of snow depth development, Water Resour. Res., 47, W09517, doi:10.1029/2010WR009429, 2011.

Schirmer, M., Wirz, V., Clifton, A., and Lehning, M.: Persistence in intra-annual snow depth distribution: 1. Measurements and topographic control, Water Resour. Res., 47, W09516, doi:10.1029/2010WR009426, 2011.

Schweizer, J., Bruce Jamieson, J., and Schneebeli, M.: Snow avalanche formation, Rev. Geophys., 41, 1016, doi:10.1029/2002RG000123, 2003.

Simenhois, R. and Birkeland, K. W.: The effect of changing slab thickness on fracture propagation, Proceedings of the $2008 \mathrm{In}-$ ternational Snow Science Workshop, Whistler, B.C., 755-760, 2008.

Sovilla, B., McElwaine, J. N., Schaer, M., and Vallet, J.: Variation of deposition depth with slope angle in snow avalanches: Measurements from Vallée de la Sionne, J. Geophys. Res., 115, F02016, doi:10.1029/2009JF001390, 2010.

Sovilla, B., Sonatore, I., Bühler, Y., and Margreth, S.: Wet-snow avalanche interaction with a deflecting dam: field observations and numerical simulations in a case study, Nat. Hazards Earth Syst. Sci., 12, 1407-1423, doi:10.5194/nhess-12-14072012, 2012.

Trujillo, E., Ramirez, J. A., and Elder, K. J.: Topographic, meteorologic, and canopy controls on the scaling characteristics of the spatial distribution of snow depth fields, Water Resour. Res., 43, W07409, doi:10.1029/2006WR005317, 2007.

Vallet, J.: Quick Deployment Heliborne Handheld LiDAR System for Natural Hazard Mapping, 3-7 May, in: Gi4DM - Geoinformation for Disaster management Conference, Antalya, Turkey, 2011.

van Herwijnen, A. and Heierli, J.: Measurement of crack-face friction in collapsed weak snow layers, Geophys. Res. Lett., 36, L23502, doi:10.1029/2009GL040389, 2009.

Vontobel, I.: Geländeanalysen von Unfalllawinen, Master's thesis, Department of Geography, University of Zurich, 2011.

Winstral, A., Elder, K., and Davis, R. E.: Spatial Snow Modeling of Wind-Redistributed Snow Using Terrain-Based Parameters, J. Hydrometeorol., 3, 524-538, 2002. 


\section{Appendix A}

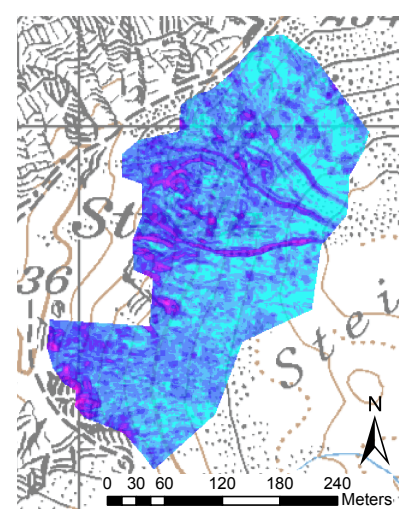

(a) DTM

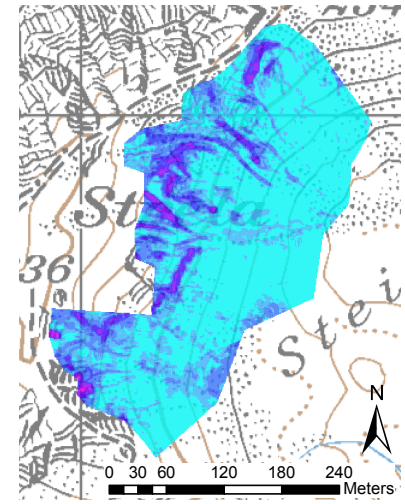

(d) 11 Jan 2012

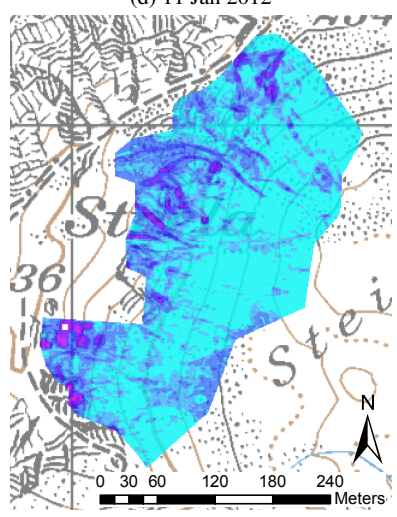

(g) 09 Mar 2012

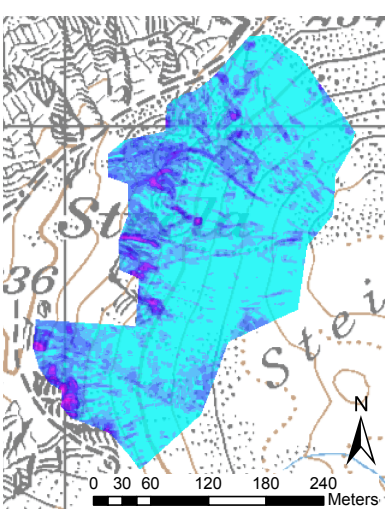

(b) $02 \mathrm{Feb} 2011$

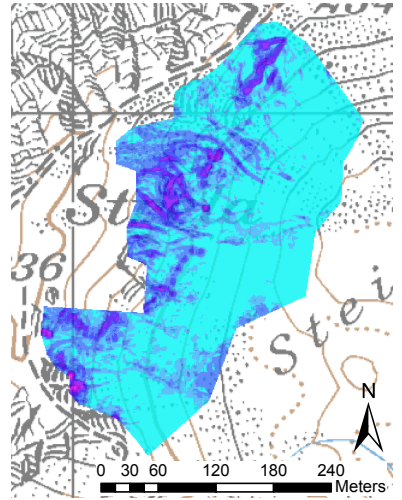

(e) $13 \mathrm{Feb} 2012$

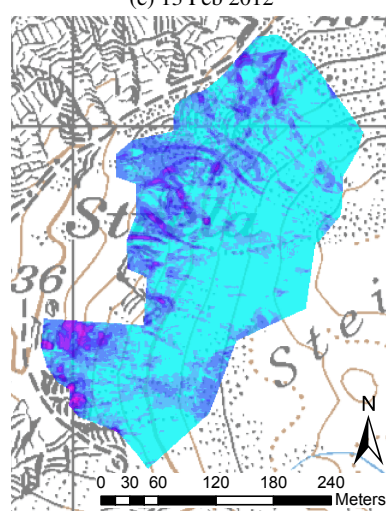

(h) 20 Mar 2012

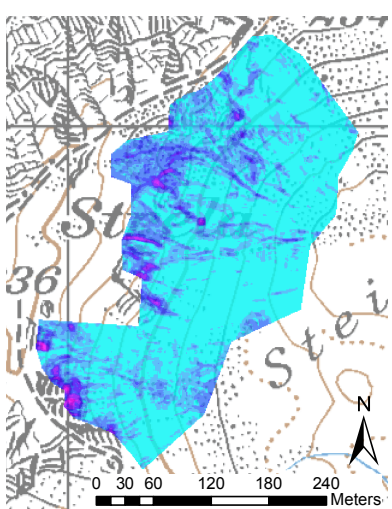

(c) 01 Mar 2011

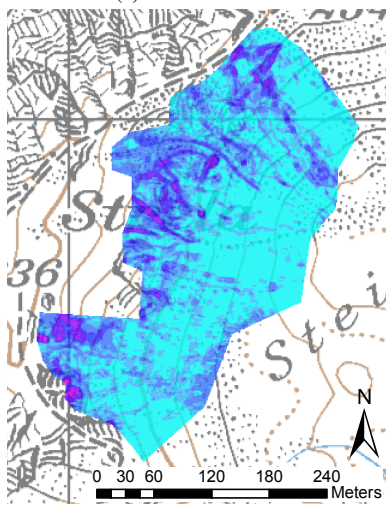

(f) $04 \mathrm{Mar} 2012$

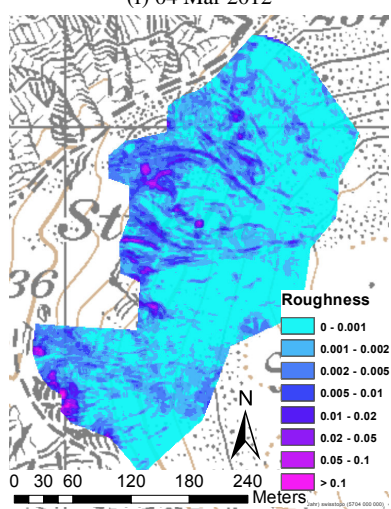

(i) 10 Jan 2013

Fig. A1. Surface roughness of summer terrain and winter terrain at a scale of $5 \mathrm{~m}$ in the basin ST. Pixmaps ${ }^{\circledR} 2013$ swisstopo (5704 000000$)$. 


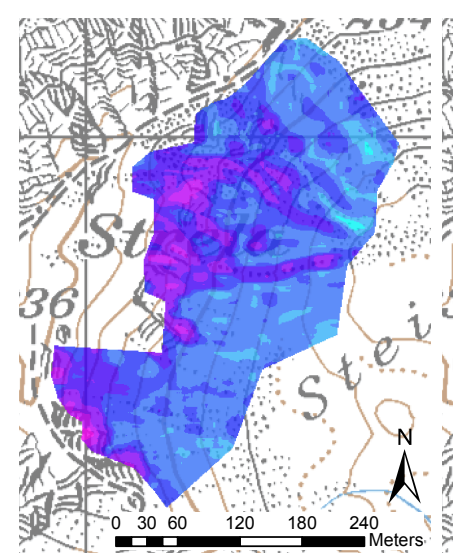

(a) DTM

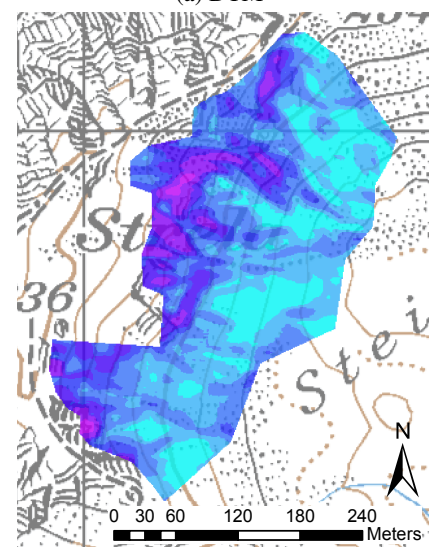

(d) 11 Jan 2012

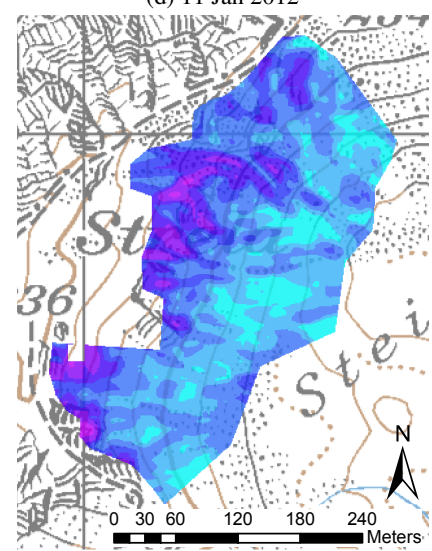

(g) 09 Mar 2012

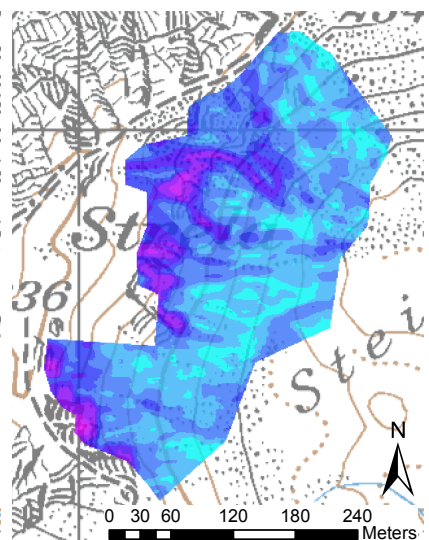

(b) $02 \mathrm{Feb} 2011$

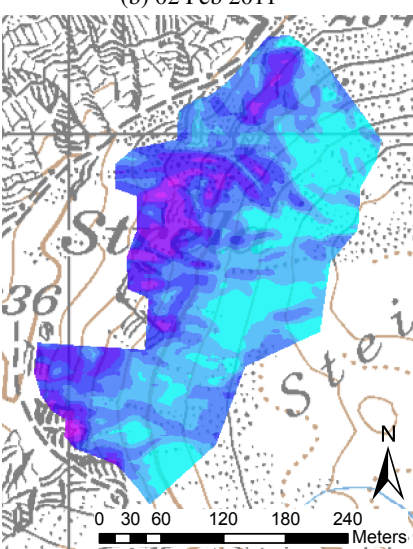

(e) $13 \mathrm{Feb} 2012$

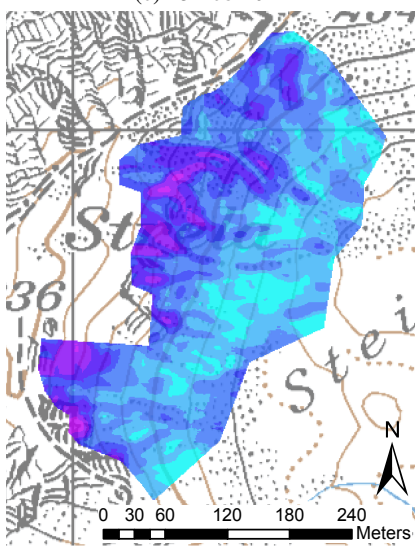

(h) 20 Mar 2012

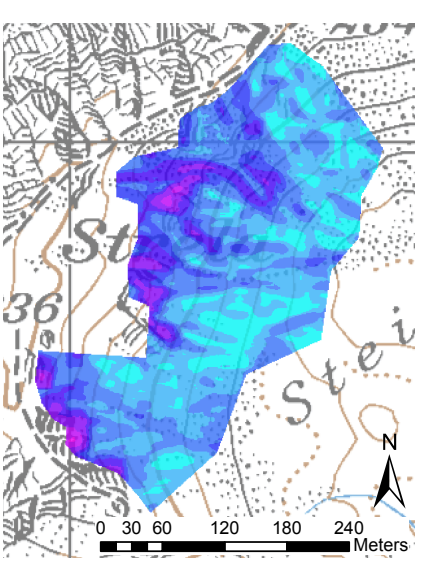

(c) 01 Mar 2011

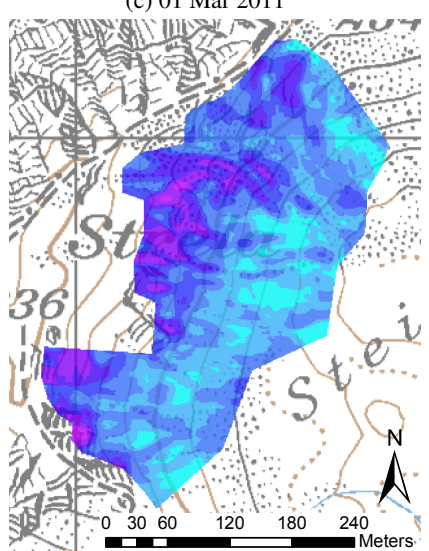

(f) 04 Mar 2012

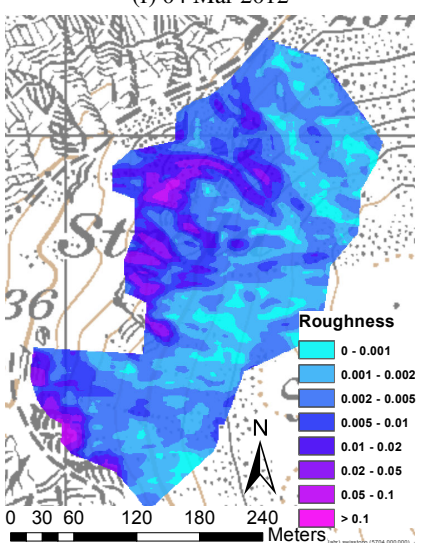

(i) 10 Jan 2013

Fig. A2. Surface roughness of summer terrain and winter terrain at a scale of $15 \mathrm{~m}$ in the basin ST. Pixmaps ${ }^{\odot} 2013$ swisstopo (5704 000 000). 


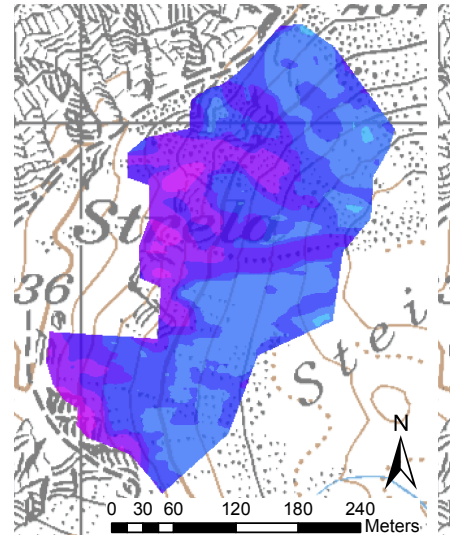

(a) DTM

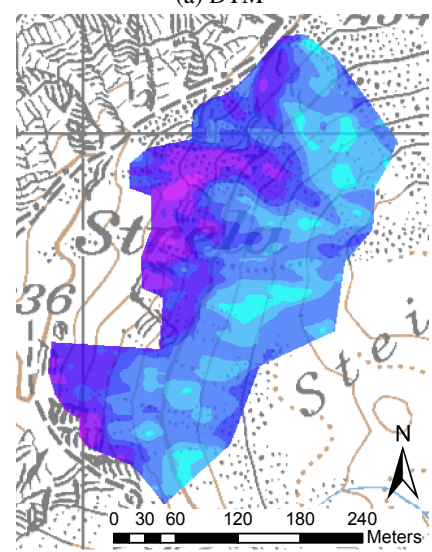

(d) 11 Jan 2012

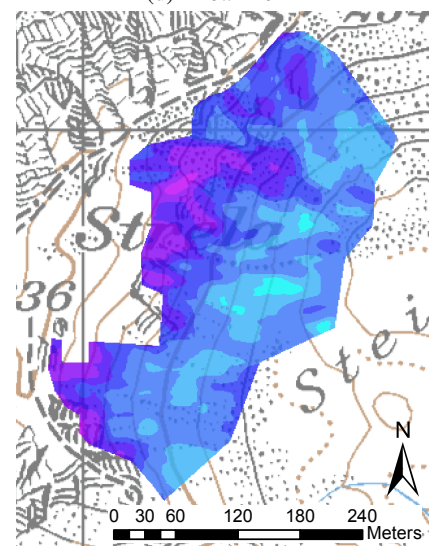

(g) 09 Mar 2012

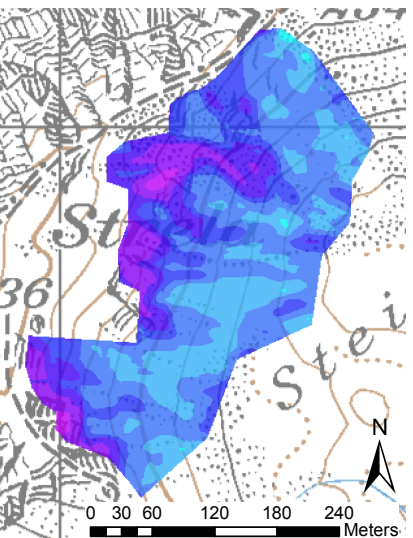

(b) $02 \mathrm{Feb} 2011$

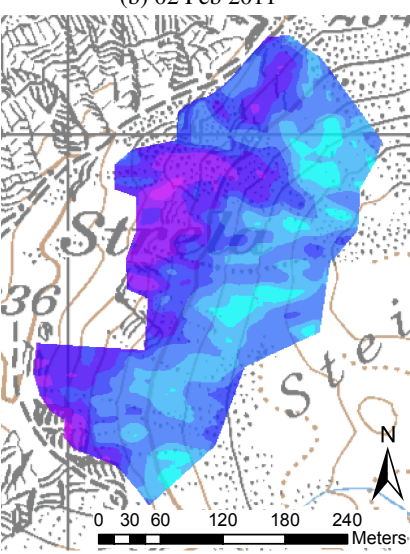

(e) 13 Feb 2012

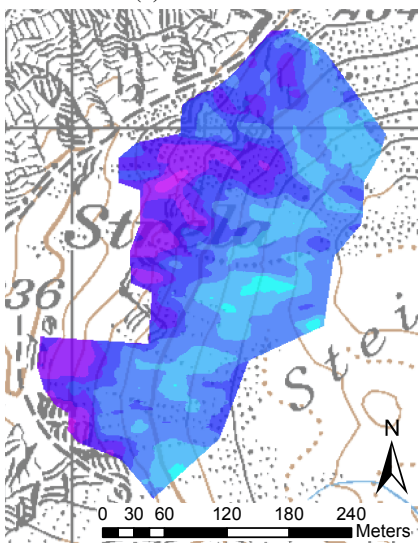

(h) 20 Mar 2012

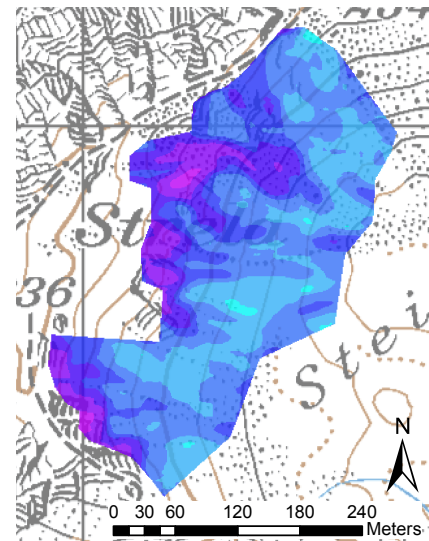

(c) 01 Mar 2011

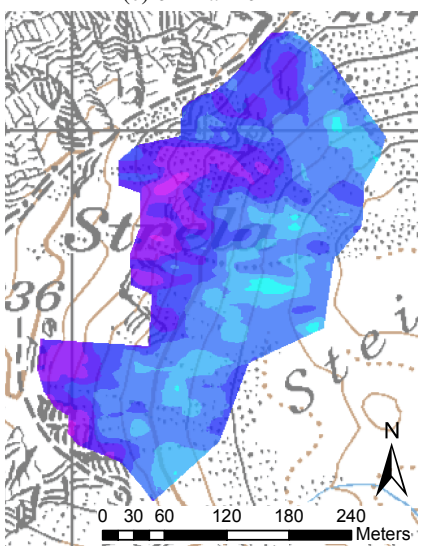

(f) 04 Mar 2012

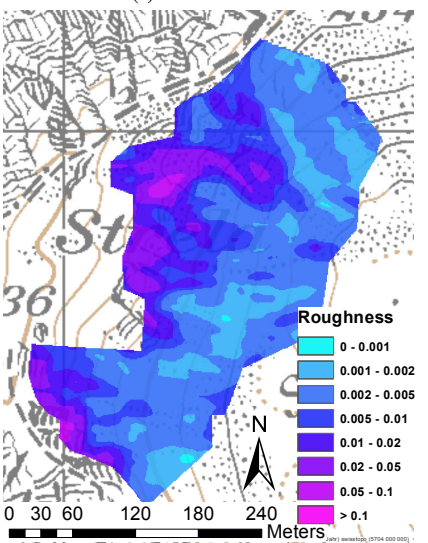

(i) 10 Jan 2013

Fig. A3. Surface roughness of summer terrain and winter terrain at a scale of $25 \mathrm{~m}$ in the basin ST. Pixmaps ${ }^{\circledR} 2013$ swisstopo $(5704000$ 000). 


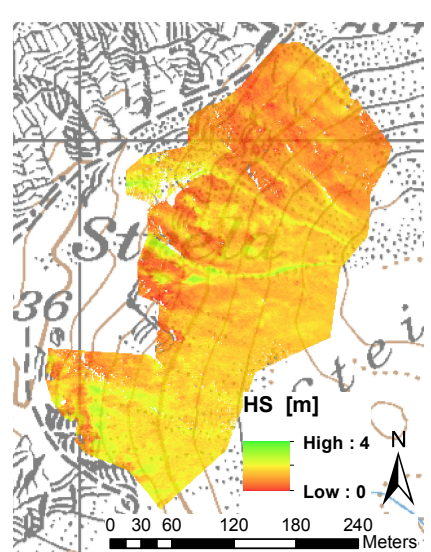

(a) 02 Feb 2011

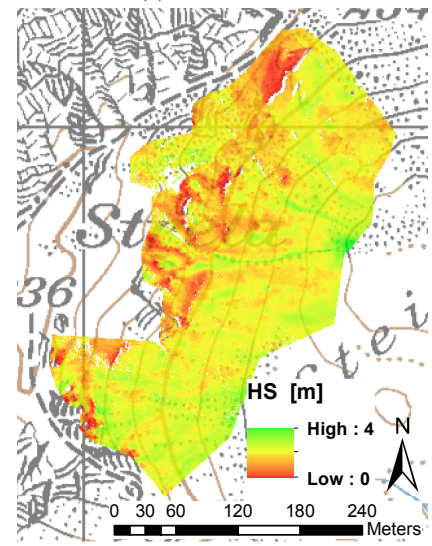

(d) 13 Feb 2012

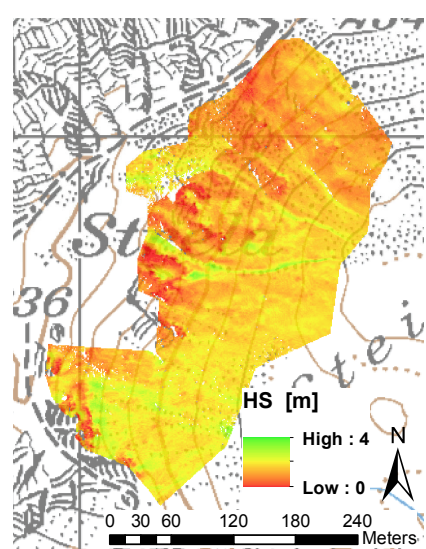

(b) 01 Mar 2011

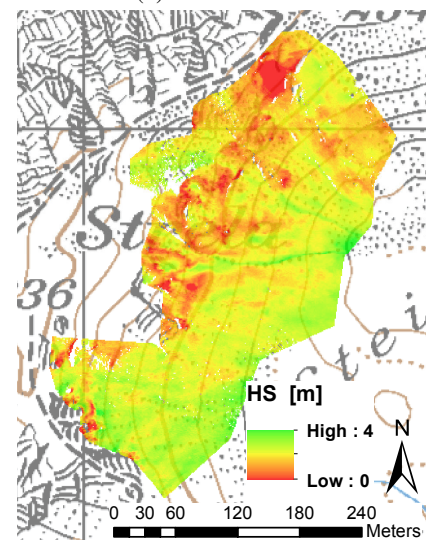

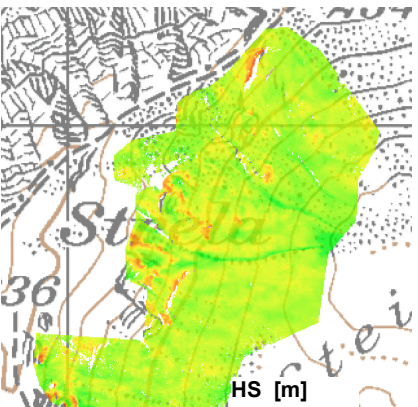

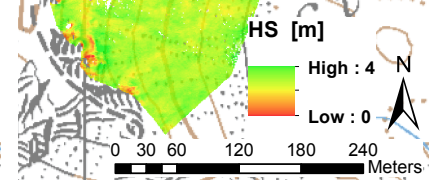

(c) 11 Jan 2012

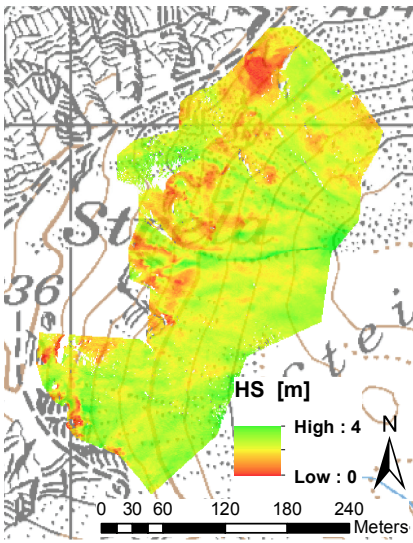

(f) 09 Mar 2012

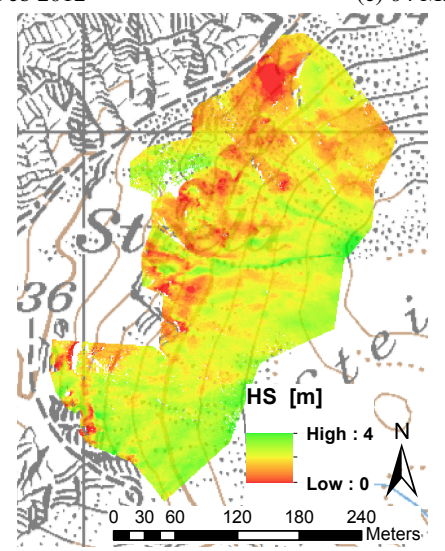

(g) 20 Mar 2012

(e) 04 Mar 2012

다.

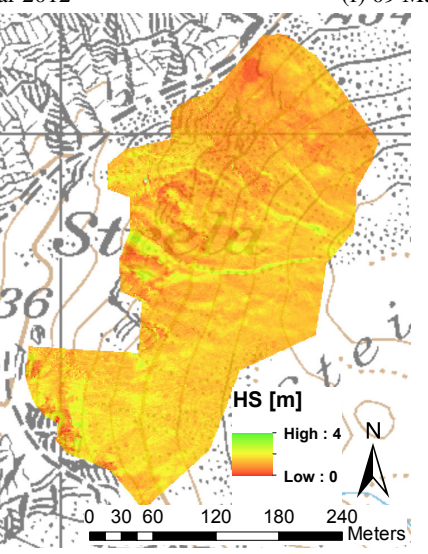

(h) 10 Jan 2013

Fig. A4. Snow depth distributions in the basin ST. Pixmaps ${ }^{\circledR} 2013$ swisstopo (5704 000000$)$. 


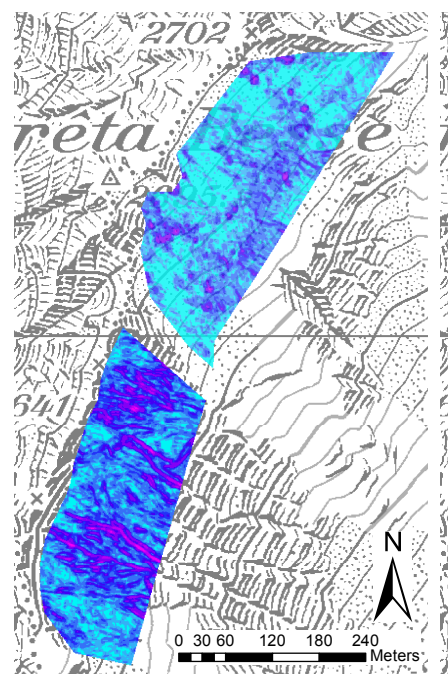

(a) DTM

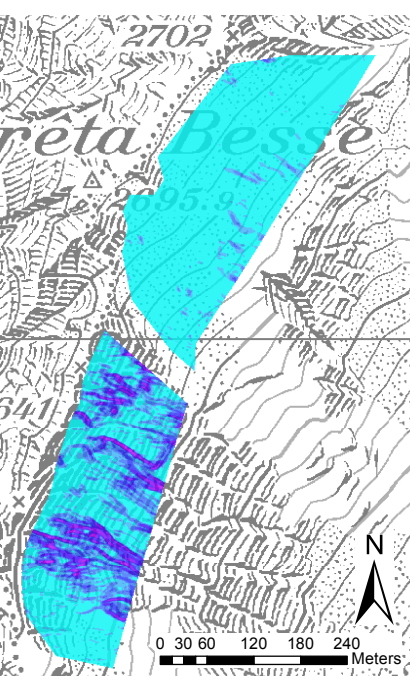

(b) 08 Mar 2006

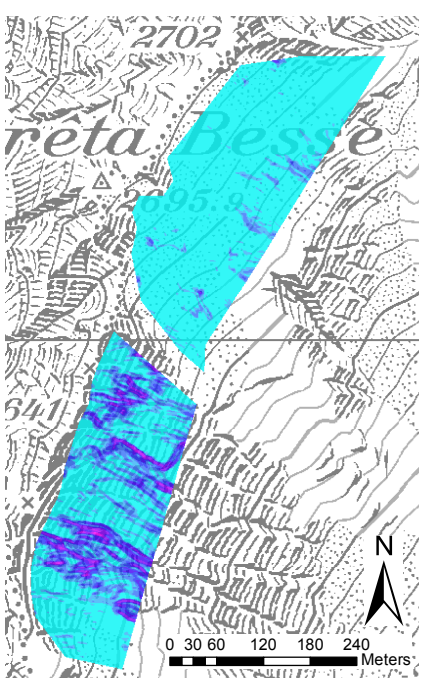

(c) 25 Jan 2009

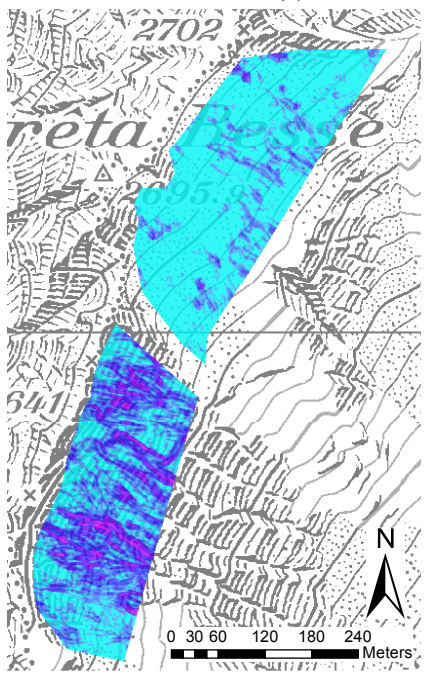

Roughness

$0-0.001$

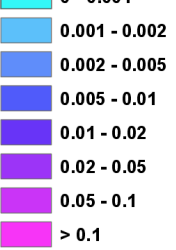

(d) 08 Dec 2011

Fig. A5. Surface roughness of summer terrain and winter terrain at a scale of $5 \mathrm{~m}$ in basins $\mathrm{CB} 1$ and CB2. Pixmaps ${ }^{\circledR} 2013$ swisstopo $(5704$ 000 000). 


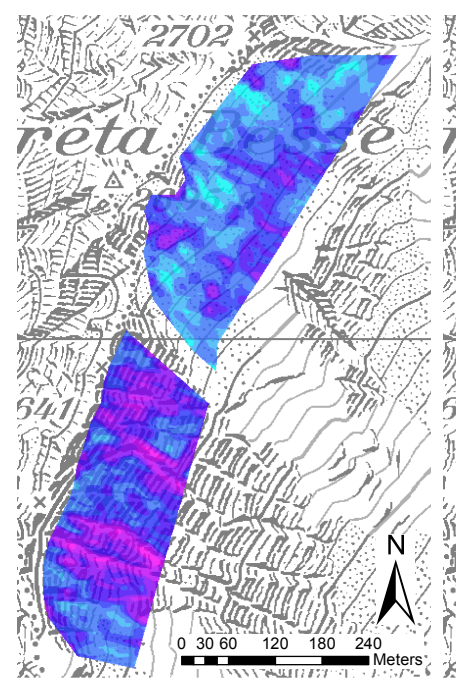

(a) DTM

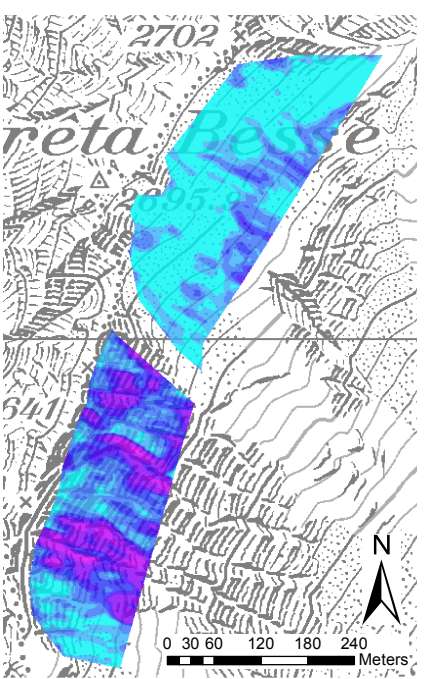

(b) 08 Mar 2006

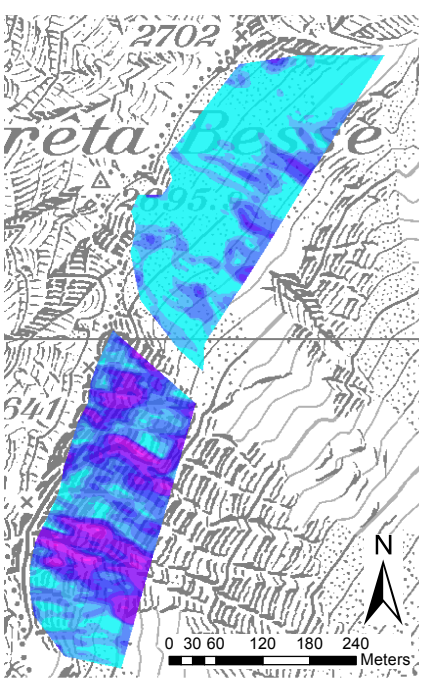

(c) 25 Jan 2009

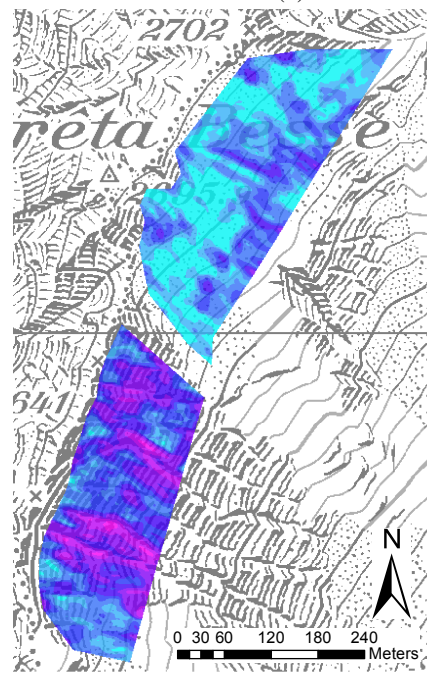

Roughness

$0-0.001$

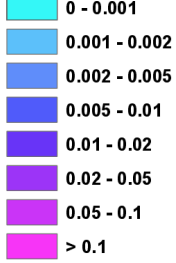

(d) 08 Dec 2011

Fig. A6. Surface roughness of summer terrain and winter terrain at a scale of $15 \mathrm{~m}$ in basins CB1 and CB2. Pixmaps ${ }^{\circledR} 2013$ swisstopo $(5704$ 000 000). 


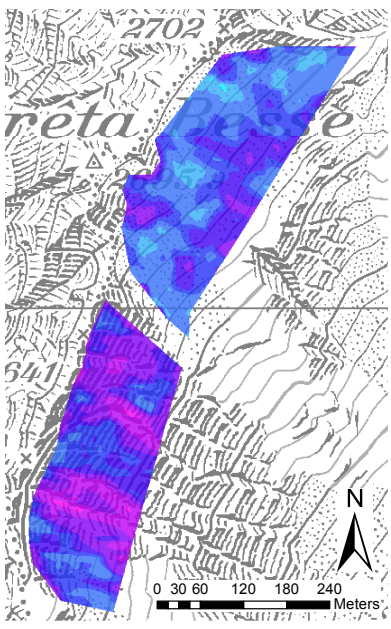

(a) DTM

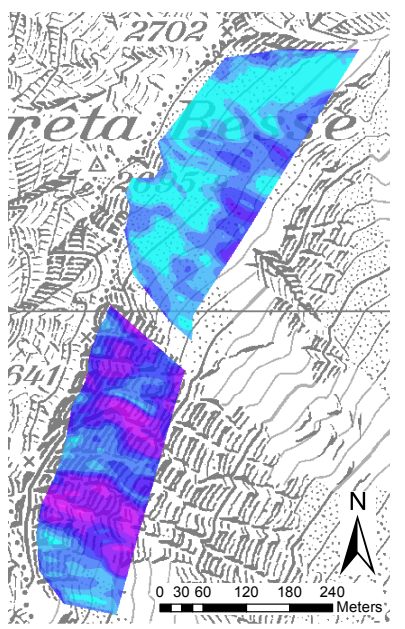

(b) 08 Mar 2006

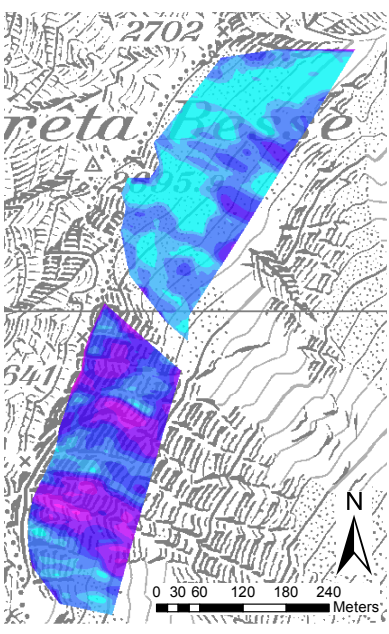

(c) 25 Jan 2009

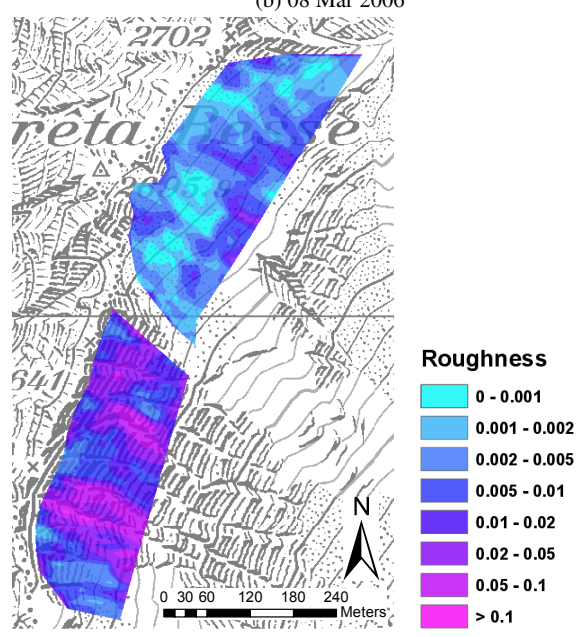

(d) 08 Dec 2011

Fig. A7. Surface roughness of summer terrain and winter terrain at a scale of $25 \mathrm{~m}$ in basins CB1 and CB2. Pixmaps ${ }^{\circledR} 2013$ swisstopo $(5704$ $000000)$.

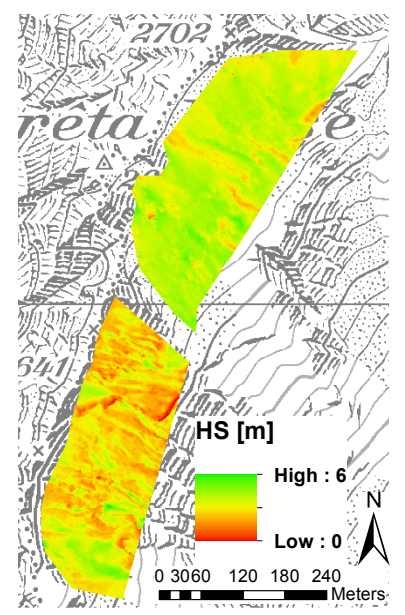

(a) 08 Mar 2006

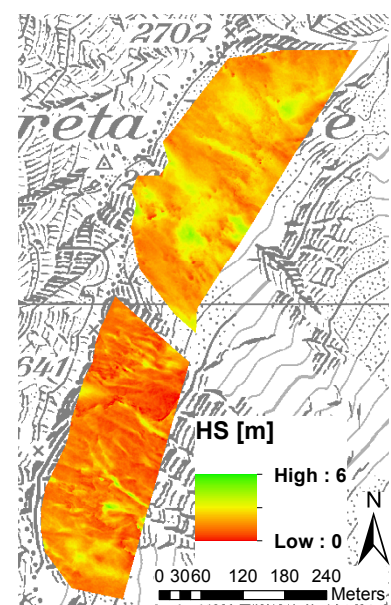

(b) $25 \operatorname{Jan} 2009$

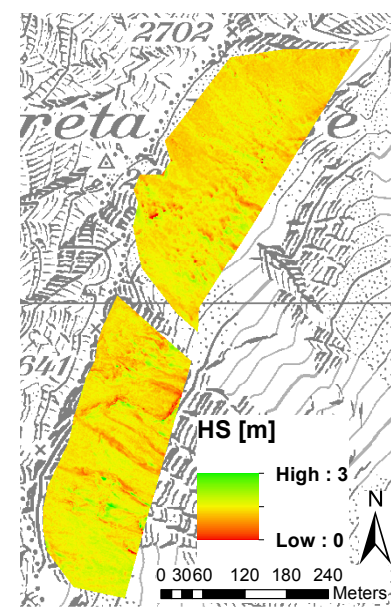

(c) 08 Dec 2011

Fig. A8. Snow depth distributions in the basins CB1 and CB2. Pixmaps ${ }^{\circledR} 2013$ swisstopo (5704 000000 ). 